\title{
A supplier performance evaluation framework using single and bi-objective DEA efficiency modeling approach: Individual and Cross Efficiency Perspective
}

\author{
Mohit Goswami $^{\mathrm{a} \$}$ and Abhijeet Ghadge ${ }^{\mathrm{b}}$ \\ a Operations Management Group, Indian Institute of Management Raipur, India \\ b Logistics and Supply Chain Management Group, School of Management, Cranfield University, Bedford, United
}

Kingdom

In view of complexities associated with supplier performance evaluation based on traditional business criterions (such as costs, quality levels, and delivery timelines) and emerging criterions (such as those related to environmental sustainability), we in this research evolve two different supplier efficiency measurement models that unify such criterions possessing characteristics of both desirable and undesirable outputs. The first model is a single-objective DEA efficiency assessment model wherein both types of outputs are integrated in a single composite efficiency measure. Using data from suppliers of Hyundai Steel Company, we determine composite efficiencies of each of these suppliers thus ranking them in terms of an overall efficiency score that would be useful as far as the first cut supplier discrimination is concerned. However due to relative inability of evolved single-objective efficiency model to perform trade-offs amongst desirable and undesirable outputs and, owing to unidimensionality aspects, we evolve a goal programing based bi-objective efficiency model wherein trade-offs can be performed between both conventional and emerging dimensions criterions leading to different supplier evaluations for varied scenarios. We also integrate our evolved models with the crossefficiency view of efficiency determination in order to enable the decision-makers to achieve peer-topeer evaluation and maximum discrimination amongst suppliers.

Keywords: Sustainable Supply Chain, Supplier Selection, DEA

\$ Corresponding author. Email: mgg123456@gmail.com 


\section{Introduction}

Faced with ever increasing competition, pressures from regulatory agencies, inflating wages and other evolving challenges, organizations across the globe belonging to both developed and developing economies are integrating relatively emerging criterions such as those related to green design, environmental sustainability, and other related dimensions in addition to the conventional criterions such as cost, quality, delivery, and safety in their operational, tactical and strategic decisions. In particular, the lexicon of sustainability in the value-chain of various sectors be it those of product centric industry such as automobiles or process intensive industry such as steel sector has gained traction in recent years owing to the forces related to the three primary dimensions of sustainability i.e. economic, social, and environmental (Das, 2018). Perhaps one of the most accepted definition of sustainability came from World Commission on Environment and Development (WCDM) that defined sustainability as "a development that meets the needs of the present without compromising the ability of the future generations to meet their own needs" (WCDM, 1987). Juxtaposing this definition to the broad area of supply chain results in another important research stream i.e. sustainable supply chain management (SSCM) (Mahdiloo et al., 2015). In broad terms, SSCM entails management of material, information and capital flows considering the cooperation amongst supply chain stakeholders in such a manner that objectives from all three pillars of sustainability are taken into consideration in organizational scheme of things (Seuring and Muller, 2008). In other words, a sustainable supply chain need to be able to efficiently fulfill the customer requirements without compromising the quality of human life, environment, and economic growth for current and future generations (Zhang and Awasthi, 2014). Therefore, it can be inferred that a typical SSC (sustainable supply chain) still need to consider the core concerns of a supply chain such as strategic planning, logistics, operations planning while taking into account sustainability dimensions focused at maximizing financial returns, improving social performance, and mitigating environmental aftereffects of its's core operations on the stakeholders involved.

Among all other strategic, tactical, operational and functional level decisions, selection of the right supplier(s) have a direct bearing on the success or failure of a supply chain (Lee et al., 2014). On a broader level, supplier selection has a direct influence on the competitive advantage of the focal company in terms of impact on cost, quality, delivery timeline and so on. However, from other emerging perspectives as well, supplier selection is an important business decision in that optimal supplier selection would have to balance the business objectives pertaining to such types of criterions. One such instance of the importance associated with such emerging criteria - social dimension of 
sustainability is illustrated by the fairly recent incidence of Jabin Inc.'s worker's protests for fair compensation at one of the Apple Inc.'s supplier in China (CNBC, 20 ${ }^{\text {th }}$ October 2017). If we view from an environmental side of such emerging criteria, the event wherein McDonald's supplier -Beijing Simplot Food Processing in China was awarded a penalty worth $\$ 629,000$ for failing to comply with the environmental regulations aptly underscores McDonald's erroneous choice of supplier selection (BBC, 30 ${ }^{\text {th }}$ April, 2015). Depending upon the context, individual dimensions of sustainability assumes primacy within a sustainable supply chain. For instance, within the stream of green supply chain management (GSCM), social factors take a backseat, while economic and environmental considerations take predominant role (Seuring et al., 2008). Similarly, in case of supply chains characterized for example by underpinnings related to offshoring, social (jobs created at offshore location/job lost at the parent company's country) and economic factors assumes predominance. The need to capture nuances related to such supply chains assumes even more importance since political leadership in many large developed countries are adopting policies that are contrary to the principles of globalization. inter alia, respective supplier's performances in terms of some measured efficiency measure being function of economic, social, and environmental has been one of key criterions for supplier selection in addition to the traditional criterions (Mahdiloo et al., 2015).

Supplier selection based on appropriate evaluations is a multi-criteria decision-making (MCDM) problem. It is a complex assessment in that it is imperative that pertinent multiple criterions be included in making the final decision. In the extant research literature, supplier selection often revolves around evaluation on several criterions such as cost, quality, delivery, flexibility, operational risks and so forth (Salem et al., 2016). Further, more often than not best suppliers are the ones associated with superior trade-offs amongst decision criterions (Opricovic et al., 2008). In extant literature, many methodologies - qualitative as well as quantitative for supplier selection based on supplier evaluation have been developed. These includes for instance analytic hierarchy process (AHP), analytical network process (ANP), artificial neural network (ANN), and case based reasoning (CBR) to name a few. From the perspective of a supplier's capability assessment leading to eventual supplier selection, there are a few issues that we seek to address through our research. First, conventional business criterions such as cost $\&$ quality and emerging criterions such as those related to sustainability \& green design is represented both in terms of desirable as well as undesirable types of outputs. More often than not handling conventional criterions such as ones related to cost and quality requires minimization and maximization approach respectively implying that lower the value of costs associated with a particular DMU (decision making unit), better the efficiency of that DMU. On the other side of spectrum, higher the 
value of quality level associated with a DMU, better the efficiency. Similarly, from an emerging criteria standpoint, both desirable and undesirable types of outputs concern with criterions such as number of green features in a product, $\mathrm{CO}_{2}$ footprint generated in producing a product and so forth. Therefore, in order to unify these two types of outputs related to both conventional and emerging criterions, it is imperative that a pragmatic mathematical model be devised in such a manner that a composite efficiency score pertaining to different suppliers can be ascertained. From a theoretical standpoint, composite scores are intended to reflect multidimensional aspects that cannot be captured by a single indicator and therefore have benefits like capacity to summarize information, the facility to interpret results compared with a battery of separate indicators, and the capacity to reduce the visible size of a set of indicators without dropping the underlying base information (Nardo, et al., 2018). This composite score would be beneficial as far as first-cut discrimination between efficient and non-efficient suppliers are concerned. More often than not supplier evaluation is not a single step process rather a bi-step process in that tradeoffs amongst different types of criterions need to be performed (Yoon, et al., 2018 and Salem et al., 2016). Moreover, considering both desirable and undesirable type of output goals associated with conventional and emerging criterions, it is also imperative that: a) objective function be modeled considering both types of criterions; and b) these two objective functions be unified in such a way that minimizing the deviation from the targeted values corresponding to different output types would be our objective. This approach would aid in that: i) composite score can be achieved for different suppliers (that can be used in conjunction with that yielded from the single objective efficiency model) and ii) trade-offs can be performed between desirable and undesirable type of outputs. These trade-offs would be useful as far as ascertaining the efficiency frontier is concerned. Finally, most of the extant research when dealing with desirable and undesirable type of outputs simultaneously has adopted a rather indirect approach in that undesirable outputs served as pseudo-inputs in determination of technical efficiencies of respective DMUs. This approach has a key limitation in that transformation in measurement scale is required as far as dealing with undesirable output is concerned (Zanella et al., 2015). To these end, we posit the following research questions.

a) How can we model the supplier selection problem from an efficiency modeling and evaluation perspective such that a composite type of efficiency score can be derived taking into account both desirable and undesirable type of outputs belonging to both emerging as well as conventional criterions?

b) How can trade-offs be performed between pool of desirable and undesirable type of outputs considering varying level of importances for the two types? 
c) How can we model the simultaneity of desirable and undesirable outputs without having to consider transformation in measurement scale of the undesirable outputs?

d) How can we achieve peer-to-peer comparison and maximum discrimination amongst DMUs?

To address these three primary research questions and thus aiding purchasing and supply chain managers, we adopt an efficiency view of supplier evaluation. In particular, we augment the work carried out by Mahdiloo et al. (2015) that evolved the DEA (data envelopment analysis) based modeling to incorporate the dimensions of sustainability in suppliers' efficiency evaluation. When encountering the conventional and emerging dimensions within a supply chain, the constituent output factors can be incongruent to each other. For instance, profitability of supplier (indicative of economic dimension) and $\mathrm{CO}_{2}$ emissions associated with supplier (indicative of environmental dimension) lie at the two ends of the spectrum in that profitability belongs to desirable output type; while $\mathrm{CO}_{2}$ emission essentially is undesirable output. Unifying two such classes of outputs becomes a challenge in the overall efficiency assessment of suppliers particularly when we attempt to model the problem from a composite efficiency standpoint. Therefore, in this research, we evolve two different types of mathematical models namely: i) single objective efficiency model and ii) bi-objective efficiency model to rationalize the measurement of efficiency for the suppliers under consideration. The evolved models are illustrated employing the data set of Hyundai Steel Company's suppliers as introduced by the work of Dotoli et al., (2015). The evolved models are also integrated with the cross-efficiency view of suppliers to achieve maximum discrimination and peer-to-peer comparison. Contrasting our efficiency oriented models with respect to some well-known MCDM techniques in terms of problem and solution structure underscores several merits of our model. These merits are discussed in detail in Section 5.2 in terms of efficiency and optimality, decision criterions, solutions, resultant weights, utility, and peerto-peer evaluation.

As depicted through Figure 1(a), the scope of our research lies at the intersection of sustainable supply chain management, supplier performance analysis, supplier selection, and DEA modeling.

$<<$ Insert Figure 1 here $>>$

Remainder of the article is arranged as follows. Section 2 presents a review of recent and relevant research literature. Section 3 details the developed model followed by Hyundai Steel Company's case in Section 4. Section 5 presents discussions and implications of our research. Finally, conclusions and future research directions are presented in Section 6. 


\section{Literature review}

The research into the sustainability component of supply chain has particularly gained prominence in the last 7-8 years or so. The extant research literature reviewed in this article pertains primarily to two broad research streams viz. supplier selection in sustainable supply chain and DEA efficiency modelling in supplier selection. In this section, we present some of the relevant research pertaining to the two streams.

\subsection{Supplier selection and evaluation in sustainable supply chain}

Shaw et al. (2016) in a departure from traditional supply chain performance parameters such as cost, quality, and lead time considered carbon emission as an important parameter for the supplier selection problem. A fuzzy multi-objective formulation was evolved to represent the supplier selection problem. A key contribution of this work was that as opposed to many of the MCDM (multi criteria decision making) based supplier selection models for sustainable supply chain, this work quantified order quantity for a supplier corresponding to a particular level of carbon footprint. Azadi et al. (2015) devised an integrated DEA enhanced Russell measure (ERM) model in fuzzy context to select the best sustainable supplier. A key contribution of this work pertained to the fact that this research employed an integrated non-radial DEA model and evolved a new efficiency measure termed as sustainable supplier performance. Using a case study approach, this model demonstrated the efficacy of the supplier selection framework. Amindoust et al. (2012) devised a ranking model based sustainable supplier selection employing fuzzy inference method. As opposed to many such earlier work, this research considered the fuzziness in supplier selection in terms of linguistic data. The affinity of a particular supplier was gauged in terms of the overall ranking of that supplier. Moheb-Alizadeh et al. (2017) while focusing on supplier selection and order allocation considering stochastic demand evolved a mixed-integer non-linear programming (MINLP) model. As far as the efficiency of supply chain is concerned, in this model a bi-objective data envelopment analysis was carried out. An important drawback of this model however was that due to non-linear and polynomial terms considered within the integrated formulation, a lot of transformations to linear terms were carried out. Azadnia et al. (2015) while integrating the lot sizing problem into the sustainable supplier selection problem considered four different types of objective functions namely: minimization of total cost, maximization of total social score, maximization of total environmental score, and maximization of total economic qualitative score. As opposed to a standard DEA based approach, the problem formulated in this research was multi-objective in nature. From a solution standpoint, weighted sum method and augmented $\in$ constraint method was deployed to determine the Pareto solution. From a policy 
standpoint, the Pareto solution also gave an insight into the lot ordering and procurement plan. Kannan (et al., 2014) proposed a fuzzy TOPSIS framework for selecting green suppliers for a Brazilian electronics company. In particular, this research based on the empirical analysis carried out employing data from 12 available suppliers ranked each of the suppliers. The results indicated that dominant criteria driving the supplier selection were senior management commitment to sustainability initiatives, application of greening concepts in product design (i.e. reduce, reuse, recycle and reclaim) and compliance with respect to legal environmental requirements. Govindan et al. (2013) explored sustainable supply chain initiatives and examined the problem of identifying an effective model based on the Triple Bottom Line (TBL) approach (economic, environmental, and social aspects) for supplier selection operations in supply chains by presenting a fuzzy multi-criteria approach. In particular, this research used triangular fuzzy numbers to express linguistic values of experts' subjective preferences during the supplier selection process.

\subsection{DEA efficiency modeling in supplier selection and evaluation}

Karsak et al. (2014) employing a combined QFD (quality function deployment) and DEA approach tackled the supplier selection problem that was also characterized by imprecise data. In particular, this research considered relationships amongst product features and supplier attributes. One of the contributions of this work related to consideration of bounds (lower and upper) of the weights belonging to supplier attributes. Thus, this work sought to tackle the problem associated with the conventional DEA approach - unrealistic weight dispersion. Dobos et al. (2014) devised a DEA type composite indicator to aid purchasing managers rank and subsequently select the best set of suppliers. The contribution of this research lied in the modeling part of the methodological development. A crucial shortcoming of this research however was that it treated the desirable parameters (quality and reusability) and undesirable parameters (lead time, price, and $\mathrm{CO}_{2}$ emission) on the same plane. Kumar et al. (2014) proposed a green DEA approach (GDEA) that borrowed various dimensions from earlier DEA research such as weight restrictions. GDEA promoted suppliers to go green and cut down their carbon footprints and comply with local emission norms. The proposed model was illustrated using the data from a well-known automobile spare parts manufacturer in India. Dotoli et al. (2016) integrated cross efficiency data envelopment analysis and Monte Carlo approach in dealing with the supplier selection problem. A key contribution of this work was that the modeling approach such developed was able to consider nondeterministic input and output data. Park et al. (2018) proposed a novel methodology for supplier evaluation, selection and improvement using an expectation maximization 
algorithm for clustering, DEA for efficiency, and analytic hierarchy process (AHP) for importance. The evolved approach was demonstrated employing tier-one suppliers belonging to Korean automobile industry. This research augmented the extant literature in terms of introduction of new methodology for supplier selection from an efficiency view point. Tsaur et al., (2017) carried out the industry performance analysis for the TFT-LCD industry in Taiwan using a combined DEA and GRA (grey relation analysis). This study concluded that most of the companies operating in this particular industry had a downward trajectory during the period 2009-2012 as far as technology changes are concerned. A key limitation of this work however pertained to the fact that for modeling simplifications only desirable outputs types were considered - cash and net sales in this case. Wu et al., (2016) in their study based oriented around maximizing the degree of satisfaction evolved a cross-efficiency based technology selection framework. One of the key contributions of this work was that it provided unique optimal weights for each DMU. However similar to the work of Tsaur et al., (2017), this study considered only desirable outputs in context of technology selection decisions.

In this research, since we aim to model the supplier evaluation framework in such a manner that some kind of composite measure based on direct approach (as opposed to surrogate measures oriented around indirect approach) in a single-objective and bi-objective environment can be formalized. Therefore, we also examine few recent important papers that modeled such problems both in a direct and indirect manner while considering both desirable and undesirable outputs simultaneously.

\subsection{Modeling desirable and undesirable outputs simultaneously}

\subsubsection{Direct approach}

Fukuyama et al., (2017) contributed to the extant DEA literature in that a two-stage network bank revenue function characterized by non-performing loans were developed. This work considered both the types of outputs viz. performing loans, securities investment and so forth as desirable output and nonperforming loans such undesirable output in gauging the efficiency of Japanese banks. Balezentis et al., (2016) in their study of Lithuanian economy approaching the goals of sustainable energy and climate change mitigation evolved a DEA based environmental performance index. Although this study considered both type of outputs viz. desirable and undesirable in context of devising an environmental index; nonetheless a crucial limitation arising out of this study pertained to non-inclusion of other economic and business dimensions. This study concluded that petroleum and air transport sectors

appeared to be the worst-performing group out of major sectors. Zanella et al. (2015) employing one the popular ways of modeling DMU's efficiencies - directional distance function evolved in such a 
manner that undesirable outputs could be integrated with composite efficiency measure. However, this study's primary limitation pertained to the fact that trade-offs could not be performed between undesirable output set and desirable output set. D'Inverno et al., (2018) in their study related to comparison of efficiencies of wastewater treatment plants utilized the direct efficiency modeling approach. The approach in this study considered removal of as many contaminants as possible to be the main objective in context of efficiency modeling and therefore considered both good outputs volume of water being processed and bad outputs - quantity of nitrogen remaining in the treated water. Rashidi et al., (2015) in their research related to assessment of green indicators and potential in energy saving in context of abatement in undesirable output evolved a novel measure called green index that essentially reflects eco-efficiency of OECD member countries. However, a major limitation of this study was that in doing so authors primarily considered dimensions related only to environment and not those related to economic and financial aspects - crucial set of considerations.

\subsubsection{Indirect approach}

Indirect approaches of modeling efficiency often assume undesirable outputs are pseudo-inputs and thus therefore assumes their strong disposability and null-jointness (D'Inverno et al., 2018). An et al., (2015) in their study related to efficiency study for commercial banks in China used a two-stage DEA model. The mathematical model evolved in this study was based on a slack-based efficiency measure in that two stages viz. deposit generation stage and deposit-utilization stages were considered while considering both desirable and undesirable outputs simultaneously. Even though banks could be differentiated with each other in terms of efficiencies, a key limitation associated with this study was that in the absence of a composite measure, comparison amongst banks in terms of surrogate measure did not align with the pertinent performance variables in banking. Zanella et al. (2015) evolved an indirect approach of treating undesirable outputs built on the model proposed by Charnes, Cooper and Rhodes (1978) using the big- $M$ transformation. Although, the method was demonstrated effectively in terms of discriminating amongst inefficient and efficiency supplier, it rankings based on indirect efficiency score changed for different values of $M$. Adler et al., (2016) in their study related to accounting for externalities and disposability proposed an indirect measure anchored in economicenvironment distance. The contribution of this work related to the additive type of model that benchmarked DMUs along eco-environmental frontier. Although this work did not evolve any composite efficiency; nonetheless the frontier evolved served as discriminating amongst different DMUs. 
The commonality and contrast of our research with some relevant and recent research has been captured in Table 1(a).

$<<$ Insert Table 1 here $>>$

\subsection{Research gaps and contributions of our study}

a) Two-proposed models i.e. single-objective efficiency model and bi-objective efficiency model evolved in this research seek to encompass both desirable and undesirable type of outputs in that dimensions related to conventional business criterions as well as those related to emerging criterions such as sustainability can be unified together. The evolved models can provide supply chain managers a better understanding on the application of sustainable supply chain evaluation.

b) Unlike the work of Dobos et al. (2014) that treated desirable and undesirable output parameters on the same plane, we discriminate between undesirable and desirable outputs related to the sustainability dimensions in that this differentiated treatment is prudent reflection of approach required for arriving at a composite efficiency score in case of a single-objective efficiency modeling in context of sustainability considerations in supplier evaluation.

c) Unlike the work of Mahdiloo et al., (2015), through the post-processing of results based on the single-objective efficiency model, we are able to identify combined/ paired/ individual buckets of sustainability dimensions wherein respective suppliers are dominant. Further within each bucket also, individual suppliers are ranked thus aiding the supply chain managers to identify which suppliers would be desirable corresponding to which combination of conventional and emerging criterions' related scenarios.

d) In order to mitigate the limitations associated with consideration of equal importances for both desirable and undesirable outputs in case of single-objective efficiency model, we further evolve a biobjective efficiency model \{focused on minimizing the deviations from ideal value(s)\} where the two types of outputs are assigned discrete and differential weightages thus resulting in supplier efficiency scores under different trade-off scenarios between desirable and undesirable outputs.

e) From a methodological point of view, our work considers both conventional and emerging criterions simultaneously. This is in contrast to the contributions of Mahdiloo et al. (2015) that though took into account technical, environmental and social parameters of suppliers under study, but nonetheless evolved a composite ranking based on supplier rankings determined considering the three parameters one at a time. Moreover, in order to achieve peer-to-peer comparison and maximum discrimination 
amongst suppliers, our study in contrast to the study of Zarbakhshnia et al. (2018) considers an crossefficiency view of the problem as well. Thus, our study takes a much more encompassing view of the supplier selection problem in presence of varying trade-offs between desirable and undesirable type of outputs.

\section{Model setting}

\section{Notations and Symbols}

Indices
\begin{tabular}{|l|l|}
\hline$i$ & Index for input type " $i " ; i=(1,2,3, \ldots I)$ \\
\hline$j$ & Index for desirable output type " $j " ; j=(1,2,3, \ldots J)$ \\
\hline$k$ & Index for undesirable output type " $k$ " $; k=(1,2,3, \ldots K)$ \\
\hline$s$ & Index for supplier " $s " ; s=(1,2,3, \ldots S)$ \\
\hline
\end{tabular}

Parameters

\begin{tabular}{|c|c|}
\hline$I P_{i s}$ & Input value corresponding to input type " $i$ " of supplier " $s$ ". \\
\hline$O P_{j s}$ & Output value corresponding to output type " $j$ " of supplier "s". \\
\hline$O P_{k s}$ & Output value corresponding to output type " $k$ " of supplier " $s$ ". \\
\hline$E_{S(J)}$ & Efficiency related to desirable output of supplier "s". \\
\hline$E_{S(K)}$ & Efficiency related to undesirable output of supplier "s". \\
\hline$E_{S(J K)}$ & Effective efficiency related to desirable and undesirable outputs of supplier "s". \\
\hline$C E_{S d(J K)}$ & $\begin{array}{l}\text { Cross-efficiency of supplier "s" using weights of supplier " } d \text { " considering both types of } \\
\text { outputs simultaneously }\end{array}$ \\
\hline$\rho_{S}$ & Importance of desirable output corresponding to supplier "s" expressed between 0 to 1. \\
\hline$\delta s$ & Importance of undesirable output corresponding to supplier " $s$ " expressed between 0 to 1 . \\
\hline$\lambda_{\operatorname{des}(j s)}$ & Weight of desirable output " $j$ " corresponding to supplier " $s$ ". \\
\hline$\lambda_{\text {undes }(k s)}$ & Weight of undesirable output " $j$ " corresponding to supplier " $s$ ". \\
\hline$u_{i}$ & Optimal weight of input " $i$ " resulting from single-objective model. \\
\hline$v_{j}$ & Weight of desirable input “ $j$ ” resulting from single-objective model. \\
\hline$w_{k}$ & Weight of undesirable input " $k$ " resulting from single-objective model. \\
\hline
\end{tabular}

Decision variables

\begin{tabular}{|l|l|}
\hline$\Delta_{\operatorname{des}(j s)}$ & Deviation of desirable output " $j$ " from target value for supplier " $s$ ". \\
\hline$\Delta_{\text {undes }(j s)}$ & Deviation of undesirable output " $j$ " from target value for supplier "s". \\
\hline
\end{tabular}

Let there be " $S$ " different suppliers each consuming " $P$ " inputs to produce " $J$ " desirable and " $K$ " undesirable outputs. The outputs related to indices $1,2,3, \ldots J$ are desirable output; the outputs related to indices $1,2,3, \ldots K$ are undesirable outputs. Technical efficiency of supplier " $s$ " measured in terms of desirable outputs and inputs can be represented using the following equation (Mahdiloo et al., 2015). 
$E_{S(J)}=\frac{\sum_{j \in J} v_{j} \cdot O P_{j s}}{\sum_{i \in I} u_{i} \cdot I P_{i s}}$

The value of $E_{S(J)}$ would lie between 0 and 1 .

The equivalent DEA problem can be represented using following set of equations.

$\operatorname{Max}\left\{E_{S(J)}\right\}$

s.t.

$\underline{\sum_{j \in J} v_{j} \cdot O P_{j s}} \leq 1 \quad \forall s=1,2,3 \ldots S$

$\sum_{i \in I} u_{i} \cdot I P_{i s}$

$v_{j} \geq 0 \quad \forall j=1,2,3 \ldots J$

$u_{i} \geq 0 \quad \forall i=1,2,3 \ldots I$

Constraints 3, 4, and 5 are the standard DEA constraints related to input/output conversion, nonnegativity of output weights, and non-negativity of input weights respectively. The above problem holds the form of a fractional linear programming (FLP) and using suitable transformations the problem can be transformed to a linear programming (LP) model as demonstrated below.

$\operatorname{Max}\left\{\sum_{j \in J} v_{j} \cdot O P_{j s}\right\}$

s.t.

$\sum_{j \in J} v_{j} \cdot O P_{j s}-\sum_{i \in I} u_{i} \cdot I P_{i s} \leq 0 \quad \forall s=1,2,3 \ldots S$

$\sum_{i \in I} u_{i} \cdot I P_{i s}=1 \quad \forall s=1,2,3 \ldots S$

$v_{j} \geq 0 \quad \forall j=1,2,3 \ldots J$ 
$u_{i} \geq 0 \quad \forall i=1,2,3 \ldots I$

Using the equivalent linear programming model (depicted through equations $6-10$ ) of fractional programming model (represented through equations $1-5$ ), the optimal weights of inputs and desirable outputs can be obtained. Thus, there would be $S$ number of total linear programming models. Conventional DEA model have typically modeled only outputs that are desirable in nature such as sales, profitability, market capitalization, production volumes and so forth (Kao et al., 2008; Cook et al., 2009; and Abbotta et al., 2003).

In case, the output being of undesirable nature, the pertinent technical efficiency can be represented employing the following equations.

$E_{s(K)}=\frac{\sum_{k \in K} w_{k} \cdot O P_{k s}}{\sum_{i \in I} u_{i} \cdot I P_{i s}}$

The equivalent DEA problem can be represented using following set of equations.

$\operatorname{Min}\left\{E_{s(K)}\right\}$

s.t.

$\frac{\sum_{k \in K} w_{k} \cdot O P_{k s}}{\sum_{i \in I} u_{i} \cdot I P_{i s}} \leq 1 \quad \forall s=1,2,3 \ldots S$

$w_{k} \geq 0 \quad \forall k=1,2,3 \ldots K$

$u_{i} \geq 0 \quad \forall i=1,2,3 \ldots I$

Akin to the maximization DEA problem, this problem also holds the form of a fractional linear programming and using suitable transformation the problem can be transformed to a linear programming model as illustrated below.

$\operatorname{Min}\left\{\sum_{k \in K} w_{k} \cdot O P_{k s}\right\}$ 
s.t.

$\sum_{k \in K} w_{k} \cdot O P_{k s}-\sum_{i \in I} u_{i} \cdot I P_{i s} \leq 0 \quad \forall s=1,2,3 \ldots S$

$\sum_{i \in I} u_{i} \cdot I P_{i s}=1 \quad \forall s=1,2,3 \ldots S$

$w_{k} \geq 0 \quad \forall k=1,2,3 \ldots K$

$u_{i} \geq 0 \quad \forall i=1,2,3 \ldots I$

The problem with such kind of transformation is two-fold viz. a) the transformed model is not congruent with the standard transformed DEA model; b) it would be impossible to have a realistic assessment of the technical efficiencies in case of outputs that are both desirable and undesirable type. Therefore, we require suitable transformations that can rationalize the two disparate types of efficiencies into a single formulation. However, this problem would again have two dimensions: a) converting the desirable and undesirable outputs into a single composite scale; and b) treating two types of outputs as bi-objective problem.

\subsection{Single objective efficiency model}

From the perspective of selection of supplier with best efficiency score, the LP models represented through equations (6-10) and (12-15) can be fused together having the following effective efficiency term (Daultani et al., 2015).

$$
E_{s(J K)}=\left[\frac{\sum_{j \in J} v_{j} \cdot O P_{j s}-\sum_{k \in K} w_{k} \cdot O P_{k s}}{\sum_{i \in I} u_{i} \cdot I P_{i s}}\right]
$$

The equivalent DEA problem can be represented using following set of equations.

$\operatorname{Max}\left\{E_{S(J K)}\right\}$

s.t. 


$$
\begin{aligned}
& \frac{\sum_{j \in J} v_{j} \cdot O P_{j s}-\sum_{k \in K} w_{k} \cdot O P_{k s}}{\sum_{i \in I} u_{i} \cdot I P_{i s}} \leq 1 \quad \forall s=1,2,3 \ldots S \\
& v_{j} \geq 0 \quad \forall j=1,2,3 \ldots J \\
& w_{k} \geq 0 \quad \forall k=1,2,3 \ldots K \\
& u_{i} \geq 0 \quad \forall i=1,2,3 \ldots I
\end{aligned}
$$

Similar to standard DEA formulation, constraint 23 pertains to input/output conversion. While constraints 24,25 , and 26 pertains to non-negativity of undesirable outputs, non-negativity of desirable outputs, and non-negativity of inputs respectively.

The equivalent LP representation of this single objective efficiency model would be represented through the following set of equations.

$$
\operatorname{Max}\left[\sum_{j \in J} v_{j} \cdot O P_{j s}-\sum_{k \in K} w_{k} \cdot O P_{k s}\right]
$$

s.t.

$$
\sum_{j \in J} v_{j} \cdot O P_{j s}-\sum_{k \in K} w_{k} \cdot O P_{k s}-\sum_{i \in I} u_{i} \cdot I P_{i s} \leq 0 \quad \forall s=1,2,3 \ldots S
$$

$$
\sum_{i \in I} u_{i} \cdot I P_{i s}=1 \quad \forall s=1,2,3 \ldots S
$$

$v_{j} \geq 0 \quad \forall j=1,2,3 \ldots J$

$w_{k} \geq 0 \quad \forall k=1,2,3 \ldots K$

$u_{i} \geq 0 \quad \forall i=1,2,3 \ldots I$

One of the limiting aspect of the above evolved formulation is that: a) it treats both the desirable and undesirable output parameters on the same level of importance; b) trade-offs cannot be performed by varying respective importances to desirable/undesirable output parameters. Therefore, we develop the following bi-objective efficiency model that mitigates the two said problems associated with the biobjective model. 


\subsection{Bi-objective efficiency model}

In the bi-objective efficiency model, the two objective functions related to desirable and undesirable outputs would be treated as it is, and equivalent problem can be evolved representing the bi-objective problem. Consider the following bi-objective model having the following objective functions.

$$
\operatorname{Max}\left\{\sum_{j \in J} v_{j} \cdot O P_{j s}\right\}
$$

$$
\operatorname{Min}\left\{\sum_{k \in K} w_{k} \cdot O P_{k s}\right\}
$$

Let $\lambda_{\text {des }(j s)}$ be the optimal weight value corresponding to desirable output " $j$ " of supplier " $s$ " when the model is solved as single efficiency objective model (known as target value for the desirable output “ $j ") ; \lambda_{\text {undes(ks) }}$ denotes the optimal weight value corresponding to the undesirable output " $j$ " for supplier " $s$ " when the model is solved as single objective model (target value for the undesirable output " $j$ "). We evolve the bi-objective efficiency model in such a manner that the objective now would be to minimize the deviations from these targets values (Nepal et al., 2012). Mathematically, let $\rho_{s}$ and $\Delta_{\operatorname{des}(j)}$ be the weight of the desirable output(s) and deviation of a particular output " $j$ " from target value respectively for supplier " $s$ " respectively. Similarly, let $\delta_{s}$ and $\Delta_{\text {des }(k s)}$ be the weights of the undesirable output(s) and deviation of a particular output " $j$ " from target value respectively for supplier " $s$ " respectively. Then the equivalent formulation for the bi-objective model would be as follows.

$\operatorname{Minimize}\left[\rho_{s}\left(\frac{\sum_{j \in J} \Delta_{\operatorname{des}(j s)}}{\sum_{j \in J} \lambda_{\operatorname{des}(j s)}}\right)+\delta_{s}\left(\frac{\sum_{k \in K} \Delta_{\text {undes }(k s)}}{\sum_{k \in K} \lambda_{\text {undes }(k s)}}\right)\right]$

s.t.

$$
\begin{aligned}
& v_{j} \cdot O P_{j s}+\Delta_{\text {des }(j s)} \geq \lambda_{\text {des }(j s)} \quad \forall s=(1,2,3 \ldots . S) ; j=(1,2,3 \ldots . J) \\
& w_{k} \cdot O P_{k s}-\Delta_{\text {undes }(k s)} \leq \lambda_{\text {undes }(k s)} \quad \forall s=(1,2,3 \ldots . S) ; j=(1,2,3 \ldots . J) \\
& \rho_{s}+\delta_{S}=1 \quad \forall s=(1,2,3 \ldots . S) \\
& \Delta_{d e s(j s)} \geq 0 \quad \forall j=(1,2,3 \ldots J) ; s=(1,2,3 \ldots . K)
\end{aligned}
$$




$$
\Delta_{\text {undes }(k s)} \geq 0 \quad \forall k=(1,2,3 \ldots . K) ; s=(1,2,3 \ldots . . K)
$$

In the above formulation, $\Delta_{\operatorname{des}(j s)}$ and $\Delta_{\text {undes }(j s)}$ are the decision variables. Constraints 36 and 37 represents the goals pertaining to desirable and undesirable outputs respectively. Constraint 38 ensures that summation of importance weights belonging to undesirable and desirable outputs for a particular supplier " $s$ " is equal to 1 . Finally, constraints 39 and 40 suggest that the deviations from target values of both desirable and undesirable outputs for a supplier " $s$ " is positive. The objective function term would be normalized corresponding to different weight combinations of desirable and undesirable outputs such that efficiencies at respective weight combinations can be determined. The formulation represented through equations $35-40$ assumes the form of a weighted goal programming in that $\Delta_{\text {des }(j s)}$ and $\Delta_{\text {undes }(k s)}$ are akin to slack and surplus variable (for respective outputs) respectively. Therefore, the objective function has been appropriately formulated in a manner that minimization of slack (deviation of respective goals from optimal weight values of desirable output assuming the problem to be single objective) and maximization of surplus (deviation of goals from optimal weight values of undesirable output assuming the problem to be single objective) becomes central to our efficiency study. The resulting equivalent formulation of our bi-objective problem is different from standard maximization or minimization linear programming problem in that unlike these two types of problems, both slack and surplus type of variables exist in our equivalent weighted goal programming formulation.

\subsection{Cross efficiency view of single-objective and bi-objective efficiency model}

The two models as evolved in previous sections when used in conjunction does enable the decisionmaker to have a holistic assessment of the DMUs under consideration. The single-objective and biobjective model together yield a composite efficiency for benchmarking purpose with varying tradeoffs between desirable and undesirable output set. However, the two models suffer from an important limitation in that peer-to-peer efficiency study cannot be carried out. Further, when traditional DEA is not able to ranks those DMUs having an efficiency score of 1 or same efficiency scores (Wang et al., 2016). Therefore, integrating cross-efficiency method with our evolved models (wherein efficiencies of individual DMUs can be obtained by linking weights of all DMUs) would be an important component of our research. Integrating the cross-efficiency view with our evolved models would serve 
two key objectives i.e. enable the decision-makers to perform: a) peer-to-peer comparison; and b) achieve maximum discrimination in that all DMUs can be completely ranked.

In order to integrate the cross-efficiency perspective with the two earlier evolved formulations, we adopt the viewpoint of Oukil and Amin (2016). Let $C E_{s d}(J K)$ be the cross-efficiency of DMU " $s$ " using optimal weights of DMU " $d$ " (obtained using the single-objective formulation) such that $s \neq d$, then matrix presented in Table 1(b) demonstrates pertinent cross-efficiencies.

The resulting single-objective formulation with cross-efficiency view would be formulated as below.

$$
\operatorname{Max}\left[\sum_{j \in J} v_{j d} \cdot O P_{j s}-\sum_{k \in K} w_{k d} \cdot O P_{k s}\right]
$$

s.t.

$$
\sum_{j \in J} v_{j d} \cdot O P_{j s}-\sum_{k \in K} w_{k d} \cdot O P_{k s}-\sum_{i \in I} u_{i d} \cdot I P_{i s} \leq 0 \quad \forall s=1,2,3 \ldots S
$$

$\sum_{i \in I} u_{i d} \cdot I P_{i s}=1 \quad \forall s=1,2,3 \ldots S$

$E_{d(J K)} \cdot \sum_{i \in I} u_{i d} \cdot I P_{i s}=\left(\sum_{j \in J} v_{j d} \cdot O P_{j s}-\sum_{k \in K} w_{k d} \cdot O P_{k s}\right)$

$v_{j d} \geq 0 \quad \forall j=1,2,3 \ldots J$

$w_{k d} \geq 0 \quad \forall k=1,2,3 \ldots K$

$u_{i d} \geq 0 \quad \forall i=1,2,3 \ldots I$

In the above formulation, equation 41 yields the composite cross-efficiency score considering pertinent weights of supplier " $d$ ". Equation 42, 43, and 44 considers the pertinent weights of supplier " $d$ ".

Similar to fusing cross-efficiency principle in the single-objective efficiency model, we can integrate cross-efficiency aspect with the equivalent bi-objective formulation illustrated in section 3.2

The resulting formulation is illustrated through the following set of equations. 
$\operatorname{Minimize}\left[\rho_{s}\left(\frac{\sum_{j \in J} \Delta_{\operatorname{des}(j s)}}{\left.\sum_{j \in J} \lambda_{\operatorname{des}(j d)}\right)}\right)+\delta_{s}\left(\frac{\sum_{k \in K} \Delta_{\text {undes }(k s)}}{\left.\sum_{k \in K} \lambda_{\text {undes }(k d)}\right)}\right]\right.$

s.t.

$\lambda_{\text {des }(j d)} \cdot O P_{j s}+\Delta_{\text {des }(j s)} \geq \lambda_{\text {des }(j s)} \quad \forall s=(1,2,3 \ldots . . S) ; j=(1,2,3 \ldots . J) ; s \neq d$

$\lambda_{\text {undes }(k d)} \cdot O P_{k s}-\Delta_{\text {undes }(k s)} \leq \lambda_{\text {undes }(k s)} \quad \forall s=(1,2,3 \ldots . S) ; j=(1,2,3 \ldots . J) ; s \neq d$

$\rho_{S}+\delta_{S}=1 \quad \forall s=(1,2,3 \ldots . . S)$

$\Delta_{\text {des }(j s)} \geq 0 \quad \forall j=(1,2,3 \ldots J) ; s=(1,2,3 \ldots . K)$

$\Delta_{\text {undes }(k s)} \geq 0 \quad \forall k=(1,2,3 \ldots . K) ; s=(1,2,3 \ldots . K)$

Since, we are trying to ascertain the efficiency of supplier " $s$ " considering the weights of supplier " $d$ ", in equation $48, \lambda_{\text {des }(j)}$ is the optimal weight corresponding to desirable output " $j$ " of supplier " $d$ " when the model is solved as single efficiency objective model (known as target value for the desirable output " $j$ " corresponding to supplier " $d$ "); $\lambda_{\text {undes( }(k d)}$ denotes the optimal weight value corresponding to the undesirable output " $j$ " of supplier " $d$ " when the model is solved as single objective model (target value for the undesirable output " $j$ " corresponding to supplier “ $d$ "). $\lambda_{\operatorname{des}(j d)}$ and $\lambda_{\operatorname{des}(j d)}$ in equation 48 ensures that we ascertain the cross-efficiency of supplier " $s$ " considering the targeted weight associated with supplier " $d$ ". Inclusion of $\lambda_{\operatorname{des}(j d)}$ and $\lambda_{\operatorname{des}(j d)}$ in equation 49 and 50 ensures that desirable and undesirable outputs coefficients of supplier " $s$ " is being considered while taking into account the corresponding weights associated with that of supplier " $d$ ". The resulting cross-efficiency of supplier "s" using the weights of supplier " $d$ " - $C E_{s d}(J K)$ obtained from the modified equivalent bi-objective formulation incorporating cross-efficiency aspect can be further processed to obtain an average measure of the cross-efficiency score for a particular supplier employing the average cross efficiency score as proposed by Cook et al., (2015). The average cross-efficiency score of a supplier "s" can be computed using the following mathematical expression. 
${ }_{-} C E_{S}=\frac{\sum_{d \in S} C E_{S d(J K)}}{S}$

Figure 1(b) depicts the research schema of proposed optimization based framework detailed above detailed in section 3.1, 3.2, and 3.3. Referring to Figure 1(b), we consider both individual efficiency and cross efficiency view of single and bi-objective efficiency optimization model. The parameter values corresponding to inputs, and desirable and undesirable outputs for suppliers serve as inputs to both single and bi-objective optimization model. These two models with their own set of objective functions and corresponding constraints results in several meaningful outputs. For instance, single objective model yields optimal weights for three types of parameters (inputs, desirable, and undesirable outputs), composite efficiency for respective suppliers, and dominant efficiency buckets. Some of these outputs serve as intermediate input to the two optimization models taking into account cross efficiency evaluation. For instance, optimal weights resulting from single objective efficiency model considering individual efficiency view acts as a input to both optimization models considering cross efficiency view. Finally, incorporating peer-to-peer comparison considering cross-efficiency evaluation results in three dimensional cross-efficiency frontier with improved discrimination amongst suppliers (for both single and bi-objective models) and considering trade-offs between desirable and undesirable outputs (for bi-objective cross efficiency model).

\section{A case study - Hyundai Steel Company's suppliers' evaluation}

The Hyundai Steel Company came into being in 1953 and is in-fact the oldest steel making company in South Korea. The company is based in Incheon and Seoul, South Korea and is a part of the Hyundai automotive group. It operates in three provinces of Korea i.e. Incheon, Dangjin, and Pohang and in Chengdu province in China as well. The vision statement as listed in the company's website is clear indicator of the company's commitment to the economic, environmental, and societal value (Hyundai Steel Company, 2018).

To test the developed models in this research and capture meaningful implications, we utilize the data set related to Hyundai Steel Company's suppliers collected by the Korean National Cleaner Production Center (KNCPC) in 2012. The data is listed in Table 2.

$<<$ Insert Table 2 here $>>$ 
Referring to Table 2, clearly there are two inputs i.e. number of employees and energy consumption. As far as the desirable inputs are concerned, there are clearly three such outputs viz. sales, ROA, and environmental $\mathrm{R} \& \mathrm{D}$ investment. $\mathrm{CO}_{2}$ emission measured in $\mathrm{Kg}$. is the undesirable output. Following the convention of Cook et al., (2014) in the given dataset the two inputs would follow "less-the-better" convention. The three desirable outputs would follow "more-the-better" convention. Further, each of these outputs would lie on different planes of sustainability as illustrated by Figure 2.

$<<$ Insert Figure 2 here $>>$

For instance, stronger sales and $R O A$ for a particular supplier would in a way contribute towards increased employment positions and improved financials. Therefore, these two outputs would lie on the economic and social planes as far as emerging and conventional type of business criterions are concerned. For a supplier, higher environmental $R \& D$ investment would result in increase in the employment opportunities as well as it would further the environmental performance of the firm; therefore, this particular desirable output would lie on the social and environmental plane. Finally, it should be apparent that $\mathrm{CO}_{2}$ emission would lie along the economic and environmental plane (Mahdiloo et al., 2015) as highest emissions has both environmental and economic costs. Further, it is to be noted that suppliers' evaluation based on the performance assessment contingent upon the factors presented in this case would be $(I+J+K)$ dimensional multi-criteria decision making (MCDM) problem in that $I, J$, and $K$ are number of attributes for corresponding to economic, environmental, and social dimensions respectively.

To the test the single objective efficiency model, the linear programming model as evolved in Section 3.1 is run. It is to be noted that corresponding to 20 number of suppliers in our case considered, there would be 20 different linear models. Corresponding to each of these 20 different linear model instances, there would be a single objective function and 28 different constraints in the augmented form as enlisted in Table 3(a).

\section{$<<$ Insert Table 3 here $>>$}

Similarly, for the equivalent bi-objective formulation as represented through equations 35-40, for the 20 problem linear problem instances, there would a single objective function and total of 86 different constraints as enlisted in Table 3(b). Since both efficiency model is essentially linear programming problem, commercial solvers can be used to solve all 40 instances of the evolved linear models. For the sake of representation, one such linear model corresponding to $1^{\text {st }}$ supplier is presented in the 
Appendix Section. $v_{1}, v_{2}, v_{3}, w_{1}, u_{1}$, and $u_{2}$ are weights correspond to sales, ROA, environmental $R \& D$ investment, $\mathrm{CO}_{2}$ emission, number of employee, and energy consumption respectively. To avoid giving zero values to $v_{1}, v_{2}, v_{3}, w_{1} ; v_{1}, v_{2}, v_{3}, w_{1} \geq 10^{-6}$ are added as constraints to the model (Mahdiloo et al., 2015). The 20-different linear model corresponding to 20 different suppliers are solved in CPLEX and composite efficiency scores are determined. Further, based on the respective composite scores, suppliers are ranked. The rankings along with discarded output related to efficiency is presented in Table 4. Figure 3(a) illustrates the spread of the output weights.

$$
\begin{aligned}
& <<\text { Insert Table } 4 \text { here }>> \\
& <<\text { Insert Figure } 3 \text { here }>>
\end{aligned}
$$

Referring to Table 4, suppliers 2, 15, and 17 are ranked highest with highest possible efficiency score of $100 \%$. This is broadly consistent with rankings obtained work of Mahdiloo et al. (2015) where efficiency evaluation was done considering outputs parameters one at a time. However, in the work of Mahdiloo et al. (2015), suppliers 16 and 18 were also ranked highest. However, in our work, suppliers 16 and 18 yielded slightly lower efficiency scores and hence are ranked at 4 and 5 respectively. However, relying purely on the composite efficiency scores corresponding to 20 suppliers considered in the case example would not be without an important caveat. Considering the resulting weights related to desirable and undesirable outputs, the suppliers also need to be classified in various efficiency buckets. For instance, in case of supplier 1, $\mathrm{ROA}$ and $\mathrm{CO}_{2}$ emission are discarded in that they do not contribute to overall efficiency. These major buckets along with pertinent suppliers are demonstrated through Table 5 .

\section{$<<$ Insert Table 5 here $>>$}

Referring to Table 5, supplier 9 (even though on a composite efficiency scale is ranked 13) is dominant in respect to two of the three desirable outputs i.e. sales and $\mathrm{ROA}$ and the undesirable output i.e. $\mathrm{CO}_{2}$ emission. This implies that even though on a composite scale of efficiency, supplier 9's efficiency was only $50 \%$; nonetheless it caters to all three paired dimensions i.e. social-economic, economicenvironmental, and social-environmental vs. other suppliers (say supplier 2) having an efficiency score of $100 \%$ but catering to only social and economic dimensions. In order to circumvent the issue of relying on the composite efficiency score to make a realistic assessment of supplier's performance, it would be prudent to rather rank each supplier within the dominant efficiency categories as presented in Table 5. These rankings are given in Table 6. 
The downside to the ranking based on the single-objective efficiency model is that the importances associated with both the types of outputs i.e. desirable output and undesirable output remains the same. However, a supply chain manager would always want a trade-off solution by considering varying level of importances for both the desirable and undesirable outputs. Since single-objective model inherently assumes equal level of importances for both the desirable and undesirable outputs, it would be imperative that with varying levels of weights corresponding to the two types of outputs, a supply chain manager must be able to identify best supplier(s) in different weight ranges of desirable and undesirable outputs. The manner in which we have formulated the bi-objective efficiency model considers $\rho_{s}$ and $\delta_{s}$ as the respective weights for desirable and undesirable outputs. The bi-objective efficiency model is laid out for the 20 suppliers and corresponding 20 linear models are solved and their efficiencies captured. The variations in efficiencies of each of these 20 suppliers corresponding to different weights for desirable and undesirable outputs (with a step of 0.1) is illustrated in Figure 3(b).

Referring to Figure 3(b), all the 20 suppliers are contrasted with each other in terms of the composite efficiency by varying weights assigned to the set of desirable and undesirable outputs. The left most side corresponding to $\rho_{s}=0$ and $\delta_{s}=1$ signifies the setting wherein the undesirable output set (i.e. set containing $\mathrm{CO}_{2}$ emission) is completely dominant over desirable output set (set containing $\mathrm{ROA}$, sales, and environmental $R \& D$ investment). On the other sides of spectrum i.e. right most side corresponding to $\rho_{s}=1$ and $\delta_{s}=0$ signifies the setting wherein the desirable output set dominates the undesirable output set. When the entire importance is assigned to undesirable output set i.e. $\mathrm{CO}_{2}$ emission (with no importance being assigned to desirable outputs i.e. sales, ROA, and environmental $R \& D$ investment), supplier 14 has the highest efficiency. On the other end of the spectrum, when entire importance is assigned to desirable outputs put i.e. sales, ROA and environmental $R \& D$ investment (with no important being assigned to undesirable outputs i.e. $\mathrm{CO}_{2}$ emission), supplier 2, 15, 16, 17, 18, and 19 yields the highest efficiency. However, these two cases are two extremes scenarios for a supply chain manager. A more cogent scenario would be when equal importances are assigned to both the desirable output(s) and undesirable outputs. In such a case, supplier 14 yields the highest efficiency.

\subsection{Cross-efficiency results}

Since, we are concerned more with trade-offs associated with desirable and undesirable set of outputs, we present the results of cross-efficiency study of the bi-objective cross-efficiency formulation 
corresponding to two specific cases. First case refers to the setting wherein each of the 20 suppliers are contrasted amongst themselves under the condition that equal importances are assigned to both the desirable and undesirable set of outputs. Essentially this setting represents the middle of the spectrum wherein neither output set dominate each other. Second case refers to the setting wherein a specific supplier that is most balanced in terms of the catering effectively to all three paired dimensions i.e. social-economic, economic-environmental, and social-environmental is contrasted with respect to all other suppliers by varying weights of desirable and undesirable type of outputs. Results of the first case is demonstrated using Figure 4(a).

$<<$ Insert Figure 4 here $>>$

First Case: Referring the Figure 4(a), $Z$ axis denotes the efficiency expressed in percentage term, while axes $X$ and $Y$ denotes 20 different suppliers. It is to be noted that the cross-efficiency of a supplier " $s$ " would be maximum when efficiency determination is being carried out using its own optimal weights. In other words $C E_{s s}(J K)=E_{S}(J K)$ would hold true. Employing the $\bar{C} E_{S}$ measure, average crossefficiencies of all the suppliers are determined and resulting ranking is presented as below.

Supplier 14> Supplier 19> Supplier 12> Supplier 17> Supplier 16> Supplier 18> Supplier 2> Supplier 20> Supplier 5> Supplier 11 > Supplier 1 > Supplier 9> Supplier 15> Supplier 13> Supplier 3> Supplier 4> Supplier 10> Supplier 8> Supplier 6> Supplier 7 .

Second case: We plot the cross-efficiency scores of supplier 9 when the respective efficiency is determined employing weights of all other suppliers considering the varying weights of desirable and undesirable output set. The plot is demonstrated employing Figure 4(b).

Referring to Figure 4(b), $Z$ axis denotes the efficiency measured in percentage term. $Y$ axis represents 20 suppliers. $X$ axis represents the weightages corresponding to desirable and undesirable output set. For instance $(0.1,0.9)$ refer to the situation where-in $10 \%$ of the weightage is given to desirable output set and $90 \%$ is given to the undesirable output set.

\section{Discussions}

\subsection{Implications of study}

Selection of right supplier(s) or right set of suppliers is considered an important strategic decision that a focal manufacturer (be it an original equipment manufacturer or a process industry leader) need to 
take. Typically, supply chain managers or purchasing managers are often tasked with supplier selection decisions driven primarily by a supplier's performance evaluation. Conventional supplier selection problem is relatively easier to deal with in that supply chain managers need to consider conventional supply chain parameters such as lower costs, shorter lead times, high quality of goods and so forth. However, when dimensions related to emerging criterions such as those related to sustainability is present in the supplier's book, it is imperative that supply chain manager must be able to quantify the supplier's performance in terms of respective efficiencies. These efficiencies would aid in ascertaining the rankings thus discriminating better performing suppliers from worse performing ones. The linear model formulated as a single-objective efficiency model seeks to address this in that a composite efficiency measure is evolved that ranks the 20 suppliers listed in the case example. An obvious benefit of such a ranking is that the concerned supply chain manager would be able to extricate suppliers in terms of their respective performances. Thus, to start with the concerned supply chain manager can weed-out poor performing suppliers. However, the single composite efficiency score suffers from the problem of unidimensionality in that suppliers are ranked from a "one-size-fit-all" kind of approach in a manner that suppliers are ranked using a single measure and hence at times the obtained rankings might be conflicting. One of key problems with the unidimensionality aspect of traditional DEA models is that although rankings for DMUs (suppliers in this case) are obtained based on the efficiency value (between 0 to 100\%), the corresponding weights obtained for outputs (both desirable as well as undesirable) are often overlooked (Ouenniche et al., 2014). However, referring to the resulting weights corresponding to different output types gives an insight as to towards which output types, the model is gravitating and to what extent it is gravitating.

Therefore, in alignment with the above elaborated aspects and to circumvent the innate unidimensionality problem, further post-processing is done in that depending upon the weights achieved corresponding to each of the desirable and undesirable outputs, major efficiency buckets are identified within which individual suppliers are ranked. For instance, in case of supplier 9, sales, ROA, and $\mathrm{CO}_{2}$ emissions are dominant efficiency factors (considering respective dominant weights) even though the associated composite efficiency score is lower than many of the suppliers. From triple bottom-line perspective of sustainability, this supplier might be the most preferred as it caters to the three individual dimensions of sustainability and atleast two pairs on sustainability planes i.e. economic \& social and social \& environmental as depicted in Figure 3. This implies that supplier 9 in terms two of the individual desirable outputs i.e. sales and $R O A$, and $\mathrm{CO}_{2}$ emission might not be the best performing one on each of these individual outputs parameters but is good candidate for a compromise 
solution when these two desirable and one undesirable parameters are required to be catered to. A case in point would be one wherein a supplier is warranted to be selected having reasonable sales, acceptable level of productivity, and relatively tolerable level of $\mathrm{CO}_{2}$ emissions. When the dominant efficiency factors are sales and environmental $R \& D$ investment, supplier 18 outranks the other 7 suppliers that lie in this bucket; although from a composite score point of view supplier 18 was ranked $5^{\text {th }}$ overall. Referring to Figure 3, supplier 18 seems to be best bet in that it caters to economic-social pair (albeit to a lesser degree than supplier 9 that caters to additional desirable output - ROA as well) and socialenvironmental pair of the sustainability planes. This is a classic case of an ideal social conscious-green supplier (may be a notch below the all-inclusive supplier - supplier 9) as this supplier addresses the economic, environmental and social considerations of sustainability. Suppliers 5 and 13 in their respective buckets outranks the other two respective suppliers in the overall efficiency score; nonetheless these two suppliers are rather singular in that they only cater to only one pair on the sustainability plane i.e. social-economic.

One of the ways in which the proposed efficiency bucket would be useful to a supply chain practitioner would be that the dominant weights described above essentially represent the marginal contribution of the particular outputs influencing the utility value (i.e. composite efficiency). Therefore, these dominant weights hold the discriminating power of the particular output(s) on the particular supplier's evaluation. Thus, using these weights, the supplier chain managers can discriminate between suppliers who perform well vis-à-vis other suppliers either in terms of pertinent social, economic, environmental, or combination of these outputs. Further, the dominant weights can also be used as parameters defining the swing from best to worst on each output type as far as supplier evaluation is concerned. The supplier(s) possessing the dominant weights associated with most (ideally all outputs) output types can be perhaps considered as the ideal supplier(s) as far as the three dimensions of business criterions is concerned. One caveat that need to be kept in mind however is that the resulting weights are dominated weights as opposed to non-dominated weights. This implies that there can be a few supplier(s) who would be superior to the ideal supplier(s) on individual output criterions. Therefore, if we intend to see the supplier evaluation from an interactive optimization viewpoint, non-dominated weights would serve the research design better than the dominated weights. For instance, non-dominated weights can be utilized to generate an efficiency frontier; minimal deviation from which can be the objective as far as supplier selection is concerned.

As enumerated earlier as well, the key limitation associated with the single-objective efficiency model is that it assumes same level of importances for both desirable and undesirable type of outputs. 
However, many times supply chain managers need to perform trade-offs wherein higher importances need to be assigned to undesirable output. Therefore, bi-objective efficiency model is evolved wherein varying importances can be assigned to both type of outputs. Consider an instance, if for the purpose of quick production turnaround if upstream manufacturer needs to ensure that a particular supplier be co-located in the same city (wherein $\mathrm{CO}_{2}$ emissions are tightly regulated). In this case, ideally speaking supply chain managers should identify the best supplier by referring to Figure 4 in the zone around where weight corresponding to undesirable output(s) are much more dominant (may be 0.7 to 0.9 ) than that corresponding to desirable output(s). On the other side of the spectrum, for argument sake if the upstream manufacturer happens to be located in the rather rural setting with extremely low level of pollution (wherein $\mathrm{CO}_{2}$ emissions need not be regulated strictly), the supply chain manager can identify the best supplier by referring to Figure 4 in the zone around where weight corresponding to desirable output(s) are more dominant (0.7 to 0.9). In each of these two cases, it would not be plausible that supplier(s) yielding highest level of efficiency corresponding to weight of 1 either for desirable output(s) or undesirable output(s) be selected; since it would imply that one type of output(s) has been completely overlooked in favor of other type of output(s). A key caveat to be exercised in case of relying completely on the bi-objective efficiency model is that there is no differential importance to different outputs within a particular output type. This handicap can be dealt with to some extent by relying on the post-processing step of the single-objective efficiency model optimization such that individual buckets of sustainability pairs can be identified. In view of the above discussions it can be clearly underscored that a supply chain practitioner should use both evolved models i.e. singleobjective efficiency model and bi-objective efficiency model in conjunction to reasonably zero-down on the set of performing supplier warranting different kind of sustainability scenarios.

As enumerated in the work of Mahdiloo et al. (2015), in context of sustainable and green supply chains, the supply chain managers are often conflicted in identifying strongly performing suppliers. This conflict primarily arises from the decision to procure from suppliers at best possible cost structure while at the same time ensuring sustainability dimensions in the supplier's operations are reflected. Therefore, the two-proposed models i.e. single-objective efficiency model and bi-objective efficiency model evolved in this research and illustrated through the case example seek to encompass both conventional and emerging criterions in that social, environmental, and economic dimensions of sustainability can also be addressed. The newly evolved models can provide supply chain managers a better understanding on the application of sustainable supply chain evaluation. 
The models employed and the results obtained in the study would aid manufacturers to compare potential suppliers from two main perspectives i.e. comparison from a composite efficiency perspective and comparison from a goal oriented perspective. These differentiated comparisons would help the supply chain mangers in that they would be able to objectively account for how well a particular supplier compares with rest and with respect to efficient one(s). We also integrate the two evolved models with the cross-efficiency view of efficiency determination. The integrated formulation helps us in performing a peer-to-peer comparison while simultaneously considering desirable and undesirable output types with appropriate trade-offs. Further, the integrated formulation also enables us to achieve maximum discrimination amongst all the suppliers by relying on the average cross-efficiency measure.

\subsection{Comparison with some extant MCDM techniques}

The optimization models i.e. single objective and bi-objective considering both individual efficiency and cross efficiency view of suppliers is characteristically different from well known MCDM techniques such as TOPSIS (Technique for Order of Preference by Similarity to Ideal Solution), VIKOR (Vlse Kriterijumska Optimizacija Kompromisno Resenje), AHP (Analytical Hierarchy process) and so forth. We now discuss some of the merits associated with the models devised in this research vis-à-vis MDCM techniques. It is to be noted that the comparisons are carried out with respect to the MCDM techniques in its purest form and not with respect to hybrid MCDM techniques (such as AHP-TOPSIS). We conceptually discuss the distinctions and merits associated with our devised methods in terms of key attributes encountered in decision-making.

Efficiency and optimality: The efficiency spread (Figure 3b) - for bi-objective model considering individual efficiency view, and efficiency frontier (Figure 4) - for single and bi-objective model considering cross efficiency view is in the space of ratios of desirable/undesirable outputs and input corresponding to the twenty suppliers considered in the study. If the suppliers were to be ranked using MCDM methods, they would lie in the criterion space (seven possible criterions from MCDM perspective as listed in Table 2). Thus, a definite merit in DEA oriented approach would be that decisions makers can consider the relationships between inputs and both types of outputs (desirable and undesirable); while MCDM would treat these parameters as pure criterions without discriminating between inputs and outputs.

Decision criterions: The efficiencies and frontiers yielded in Figure 3(b) and Figure 4 are essentially ratios of multiple outputs (both desirable and undesirable types) to concerned inputs. In MCDM methods however the evaluations are essentially aggregate function (for instance distance function of 
all criterions in case of TOPIS and VIKOR). This has its own merits as far as DEA based approach is concerned in that better supplier discrimination would be achieved as efficient suppliers are the ones that perform best on a particular ratios of outputs to inputs. While in case of MCDM, a non-inferior supplier would be the one with atleast one input or one output as best.

Solution: The set of efficient units as determined by the single-objective model and efficient frontier as determined by the bi-objective model holds no relationship to the non-inferior solution(s) that results using application of MCDM techniques. Typically, efficient units resulting from DEA oriented approach are highly ranked by VIKOR method; while inefficient units resulting from DEA is given low ranking by VIKOR (Opricovic and Tzeng, 2008). In this backdrop, a definite merit that our DEA oriented approach is that it takes into account the suppliers' parameters' values that are extreme in nature (for instance number of employees for supplier 1) as opposed to traditional MCDM techniques that fail to rationalize extreme values of certain parameters.

Weights: In traditional MCDM methods, criterions weights are given by decision-makers that in turn influences ranking of better alternatives over inferior ones. In our approach however optimal weights in case of single objective model i.e. $u_{i}^{*} \mathrm{~s}, v_{j}^{*} \mathrm{~s}$, and $w_{k}^{*}$ and deviations of desirable and undesirable outputs in case of bi-objective model i.e. $\Delta^{*}{ }_{\operatorname{des}(j s)} \mathrm{S}$ and $\Delta^{*}{ }_{\text {undes }(k s)} \mathrm{S}$ does not hold relationship with respect to decision-makers' preferences. This property is particularly useful for situations wherein decision-makers are not able to express preferences of one parameter over others be it inputs related or desirable/undesirable output related.

Utility: The approach devised in our research determines the efficient supplier buckets (single objective model), trade-off efficiency frontier (bi-objective model) thus discriminating between efficient and inefficient suppliers. The potential improvement pathway for inefficient units by DEA illustrate that how a supplier needs to decrease its input(s) or increase its desirable output(s) or reduce its undesirable output(s) in order move higher in the efficiency frontier. This particular aspect is useful within DEA literature, but is of less interest within MCDM research stream.

Peer-to-peer assessment: The cross-efficiency evaluation of the two devised optimization models enables us to consider the optimal weights as inputs for determination of efficiencies for respective suppliers thus eliminating unrealistic weight schemes without predetermining any weight restrictions (Hui-hui et al., 2019). This particular feature associated with DEA based approaches presents a rather comprehensive view of the suppliers' evaluation. 


\section{Conclusions and future research directions}

This research evolves two distinct ways of modeling desirable and undesirable outputs belonging to sustainability dimensions associated with a number of suppliers of Hyundai Steel Company. The first model pertains to a single-objective efficiency model wherein by suitable transformations, we are able to unify both the desirable and undesirable outputs in terms of a single composite efficiency measure. Using the case example data and with appropriate linear models corresponding to the 20 suppliers, we determine the composite efficiency of each of these suppliers thus ranking them in terms of an overall efficiency score. However due to unidimensionality of such a composite efficiency measure, we also identify individual sustainability buckets within which particular suppliers are dominant over the other. Within each of these sustainability buckets, suppliers are further ranked. However, owing to a key limitation of the single objective efficiency model - same level of importances assigned to both desirable and undesirable outputs; we evolve a goal based bi-objective efficiency model wherein varying weights can be assigned to desirable and undesirable outputs of sustainability. By solving the resulting linear model and with appropriate trade-offs in the importances, we are able to converge on to the best performing supplier(s) corresponding to different discrete importance settings related to the sustainability dimensions.

There are some limitations to our study however. Due to relying on relatively small size and single industry, there can be limitations in generalizability. The two-proposed models should be tested in other sectors as well in order to further enrich the derived learnings. Further, our evolved models would not be able to deal with the incompleteness or fuzziness of data both of output and input. Future studies can also evaluate the evolved formulations considering Shannon entropy such that measurements related to uncertainties in rankings can be better quantified. 


\section{References}

Abbott, M., and Doucouliagosab, C., 2003, "The efficiency of Australian universities: a data envelopment analysis", Economics of Education Review, 22(1), 89-97.

Adler, N., Sinuany-Stern, Z., 2002, "Review of ranking methods in the data envelopment analysis context", European Journal of Operational Research, 140(2), 249-265.

Adler, N., and Volta, N., 2016, "Accounting for externalities and disposability: A directional economic environmental distance function", European Journal of Operational Research, 250(2016), 314-327.

Amindoust, A., and Bahreininejad, A., 2012, "Sustainable supplier selection: A ranking model based on fuzzy inference system", Applied Soft Computing, 12(6), 1668-1677.

An, Q., Chen, H., Wu, J., and Liang, L., 2015, "Measuring slacks-based efficiency for commercial banks in China by using a two-stage DEA model with undesirable output", Annals of Operations Research, 235(1), 13-35.

Azadi, M., Jafarian, M., Farzipoor Sean, R., Mirhedayatian, S., M., 2015, “A new fuzzy DEA model for evaluation of efficiency and effectiveness of suppliers in sustainable supply chain management context" Computers and Operations Research, 54(2015), 274-285.

Azadnia, A., H., Saman, M., Z., M., and Wong, K, Y., 2015, "Sustainable supplier selection and order

lot-sizing: an integrated multi-objective decision-making process", International Journal of Production Research, 53(2), 383-408.

Balezentis, T., Li, T., Streikikiene, D., and Balezentis, A., 2016, "Is the Lithuanian economy approaching the goals of sustainable energy and climate change mitigation? Evidence from DEA-based environmental performance index", Journal of Cleaner Production, 116(2016), 23-31.

Chang, S.-C., 2011, "Returns to scale in DEA models for performance evaluations", Technological Forecasting and Social Change, 8(8), 1389-1396.

Cook, W. D., and Seiford, L., M., 2009, "Data envelopment analysis (DEA) - Thirty years on", European Journal of Operational Research, 192(1), 1-17.

Cook, W., D., Tone, K>, and Zhu, J., 2014, "Data Envelopment Analysis: prior to choosing a model", Omega, 44(2014), 1-4. 
Cook, W., D., and Zhu, C., "DEA Cross Efficiency”, Data Envelopment Analysis, International Series in Operations Research \& Management Science 221, DOI 10.1007/978-1-4899-7553-9_2

Das, D., 2018, "Sustainable supply chain management in Indian organisations: an empirical investigation", International Journal of Production Research, https://doi.org/10.1080/00207543.2017.1421326

Daultani, Y., Kumar, S., Vaidya, O., S., and Tiwari, M. K., 2015, “A supply chain network equilibrium model for operational and opportunism risk mitigation", International Journal of Production Research, $53(18), 5685-5715$.

D’Inverno, G., Carosi, L., Romano, G., and Guerrini, A., "Water pollution in wastewater treatment plants: An efficiency analysis with undesirable output", European Journal of Operational Research, 269(1), 24-34.

Dobos, I., and Vorosmarty, G., 2014, "Green supplier selection and evaluation using DEA-type composite indicators", International Journal of Production Economics, 157(2014), 273-278.

Dotoli, M., Epicoco, N., Falagario, M., and Sciancalepore, F., 2015, “A stochastic cross-efficiency data envelopment analysis approach for supplier selection under uncertainty", International Transactions in Operational Research, 23(4), 725-748.

Fukuyama, H., and Matousek, R., 2017, "Modelling bank performance: A network DEA approach”, European Journal of Operational Research, 259(2), 721-732.

Govindan, K., Khodaverdi, R., and Jafarian, A., 2013, “A fuzzy multi criteria approach for measuring sustainability performance of a supplier based on triple bottom line approach", Journal of Cleaner Production, 47(2013), 345-354.

Liu, H-h., Song, Y-y., and Yang, G-1., 2019, "Cross-efficiency evaluation in data envelopment analysis based on prospect theory", European Journal of Operational Research, 273(1), 364-375.

More, D., Basu, P., 2013, "Challenges of Supply Chain Finance: A Detailed Study and a Hierarchical Model Based on the Experiences of an Indian Firm”, Business Process Management Journal, 19(4), 624-647. 
Hyundai Steel Company website at https://www.hyundai-steel.com/

Kannan, D., Jabbour, A. B., L. d., S., Jabbour, C. J., C., 2014, "Selecting green suppliers based on GSCM practices: Using fuzzy TOPSIS applied to a Brazilian electronics company”, European Journal of Operational Research, 233(2), 432-447.

Kao, C., Hwang, S-N., 2008, "Efficiency decomposition in two-stage data envelopment analysis: An application to non-life insurance companies in Taiwan", European Journal of Operational Research, 185(1), 418-429.

Karsak, E., E., and Dursun, M., 2014, "An integrated supplier selection methodology incorporating QFD and DEA with imprecise data", Expert Systems with Applications, 41(16), 6995-7004.

Kumar, A., Jain, V., and Kumar, S., 2014, "A comprehensive environment friendly approach for supplier selection", Omega, 42(1), 109-123.

Lee, K-H., Jim, J. W., 2014, “Integrating sustainability performance measurement into logistics and supply networks: a multi-methodological approach, The British Accounting Review, 46(4), 361-378.

Mahdiloo, M., Saen, R., F., and Ki-Hoon, Lee, 2015, "Technical, environmental and eco-efficiency measurement for supplier selection: An extension and application of data envelopment analysis", International Journal of Production Economics, 168(2015), 279-289.

Mavi, R., M., Saen, R., F., and Goh, M., 2018, "Joint analysis of eco-efficiency and eco-innovation with common weights in two-stage network DEA: A big data approach", Technological Forecasting and Social Change, https://doi.org/10.1016/j.techfore.2018.01.035.

McDonald's China fries supplier gets pollution fine (2015, April 2015). BBC, Retrieved from http://www.bbc.com/news/world-asia-china-32527750

Moheb-Alizadeh, H., and Handfield, R., 2017, “An integrated chance-constrained stochastic model for efficient and sustainable supplier selection and order allocation", International Journal of Production Research, https://doi.org/10.1080/00207543.2017.1413258.

More, D., and Basu, P., 2013, "Challenges of supply chain finance: A detailed study and a 
Nardo, M., Saisana M., Saltelli A., Tarantola S., Hoffmann A., and Giovannini, E., 2008, "Handbook on constructing composite indicators: Methodology and user guide", Organisation for Economic Cooperation and Development.

Nepal, B., Monplaisir, L., and Famuyiwa, O., 2012, "Matching Product architecture with supply chain design”, International Journal of Production Economics, 216(2012), 312-325.

Opricovic, S., Tzeng, G-H., 2008, “A COMPARATIVE ANALYSIS OF THE DEA-CCR MODEL AND THE VIKOR METHOD”, Yugoslav Journal of Operations Research, 19(2018), 187-203.

Ouenniche, J., and Tone, K., 2014, "Forecasting Models Evaluation Using A Slacks-Based ContextDependent DEA Framework “, The Journal of Applied Business Research, 30(5), 1477-1484.

Oukil, A., and Amin, G., R., 2016, "Maximum Appreciative cross-efficiency in DEA: A new ranking method, Computers and Industrial Engineering, 81(2015), 14-21.

Rashidi, K., and Saen, R., F., 2015, "Measuring eco-efficiency based on green indicators and potentials in energy saving and undesirable output abatement", Energy Economics, 50(2015), 18-26.

Salem, A., A., Awasthi, A., and Wang, C., 2016, “A Multicriteria Multistep Approach for Evaluating Supplier Quality in Large Data Sets", In: Pham H. (eds) Quality and Reliability Management and Its Applications. Springer Series in Reliability Engineering. Springer, London.

Seuring, S., and Muller, M., 2008, "From a literature review to a conceptual framework for sustainable supply chain management", Journal of Cleaner Production, 16(15), 1699-1710.

Shaw, K., Shankar, R., Yadav. S., S., Thakur, L. S., "Supplier selection using fuzzy AHP and fuzzy multi-objective linear programming for developing low carbon supply chain", Expert Systems with Applications, 39(9), 8182-8192.

Tongzon, J., 2001, "Efficiency measurement of selected Australian and other international ports using data envelopment analysis", Transportation Research Part A: Policy and Practice, 35(2), 107-122.

Tsaur, R-C., Chen, I-F., Chan, Y-S., 2017, “TFT-LCD industry performance analysis and evaluation using GRA and DEA models", International Journal of Production Research, 55(15), 4378-4391. 
Wang, Q., Hang, Y., Sun, L., and Zhao, Z., 2016, "Two-stage innovation efficiency of new energy enterprises in China: A non-radial DEA approach", Technological Forecasting and Social Change, 112(2016), 254-261.

Wang, L., Li, L., and Hong, N., 2016, “Entropy Cross-Efficiency Model for Decision Making Units with Interval Data”, Entropy, 18(10), 358.

Wu, J., Chu, J., Zhu, Q., Yin, P., and Liang, L., 2016, "DEA cross-efficiency evaluation based on satisfaction degree: an application to technology selection", International Journal of Production Research, 54(20), 5990-6007.

WCDE (World Commission on Environment and Development), 1987, "Our Common Future”, Oxford University Press, Oxford, UK.

Workers at iPhone supplier in China protest unpaid bonuses (2017, October 20). CNBC, Retrieved from $\quad$ https://www.cnbc.com/2017/10/20/workers-at-iphone-supplier-in-china-protest-unpaidbonuses.html.

Yoon, J., Talluri, S., Yildiz, H., and Ho, W., 2018, "Models for supplier selection and risk mitigation: a holistic approach", International Journal of Production Research, 56(10), 3636-3661.

Zarbakhshnia, N., and Jaghdani, T., J., 2018, "Sustainable supplier evaluation and selection with a novel two-stage DEA model in the presence of uncontrollable inputs and undesirable outputs: a plastic case study", The International Journal of Advanced Manufacturing Technology 97(2018), 2933-2945.

Zanella, A., Camanho, A., S., and Dias, T., G., 2015, "Undesirable outputs and weighting schemes in composite indicators based on data envelopment analysis", European Journal of Operational Research, 245(2), 517-530.

Zhang, Z., and Awasthi, A., 2014, "Modelling customer and technical requirements for sustainable supply chain planning", International Journal of Production Research, 52(17), 5131-5154. 


\section{Appendix}

\section{Single objective efficiency model for supplier 1}

$$
\begin{aligned}
& \max \left(119477 v_{1}+0.04046 v_{2}+67 v_{3}-43,562 w_{1}\right) \\
& \text { s.t } \\
& 119477 v_{1}+0.04046 v_{2}+67 v_{3}-43,562 w_{1}-1112 u_{1}-1267 u_{2} \leq 0 \\
& 125762 v_{1}+0.04499 v_{2}+65 v_{3}-45,000 w_{1}-118 u_{1}-968 u_{2} \leq 0 \\
& 58770 v_{1}+0.02221 v_{2}+57 v_{3}-42,400 w_{1}-458 u_{1}-1001 u_{2} \leq 0 \\
& 62989 v_{1}+0.02920 v_{2}+62 v_{3}-43734 w_{1}-416 u_{1}-1393 u_{2} \leq 0 \\
& 67088 v_{1}+0.03269 v_{2}+50 v_{3}-44890 w_{1}-413 u_{1}-1586 u_{2} \leq 0 \\
& 72318 v_{1}+0.03116 v_{2}+36 v_{3}-42913 w_{1}-430 u_{1}-1802 u_{2} \leq 0 \\
& 74626 v_{1}+0.02184 v_{2}+47 v_{3}-394383 w_{1}-426 u_{1}-1998 u_{2} \leq 0 \\
& 74476 v_{1}+0.03480 v_{2}+44 v_{3}-40078 w_{1}-452 u_{1}-1824 u_{2} \leq 0 \\
& 79710 v_{1}+0.03976 v_{2}+47 v_{3}-39500 w_{1}-503 u_{1}-1479 u_{2} \leq 0 \\
& 79384 v_{1}+0.03723 v_{2}+89 v_{3}-45023 w_{1}-498 u_{1}-1623 u_{2} \leq 0 \\
& 73124 v_{1}+0.01269 v_{2}+256 v_{3}-73124 w_{1}-192 u_{1}-1322 u_{2} \leq 0 \\
& 62529 v_{1}+0.00385 v_{2}+423 v_{3}-62529 w_{1}-171 u_{1}-831 u_{2} \leq 0 \\
& 65424 v_{1}+0.02776 v_{2}+508 v_{3}-65424 w_{1}-163 u_{1}-913 u_{2} \leq 0 \\
& 71027 v_{1}+0.04847 v_{2}+536 v_{3}-43734 w_{1}-161 u_{1}-893 u_{2} \leq 0 \\
& 74093 v_{1}+0.05140 v_{2}+570 v_{3}-44890 w_{1}-161 u_{1}-903 u_{2} \leq 0 \\
& 72830 v_{1}+0.04356 v_{2}+472 v_{3}-42913 w_{1}-162 u_{1}-778 u_{2} \leq 0 \\
& 71940 v_{1}+0.03932 v_{2}+426 v_{3}-39438 w_{1}-159 u_{1}-710 u_{2} \leq 0 \\
& 82203 v_{1}+0.02599 v_{2}+386 v_{3}-40078 w_{1}-157 u_{1}-695 u_{2} \leq 0 \\
& 55681 v_{1}+0.00001 v_{2}+376 v_{3}-39500 w_{1}-151 u_{1}-637 u_{2} \leq 0 \\
& 64839 v_{1}+0.02742 v_{2}+369 v_{3}-64839 w_{1}-151 u_{1}-781 u_{2} \leq 0 \\
& v_{1} ; v_{2} ; v_{3} ; w_{1} ; u_{1} ; u_{2} \geq 0
\end{aligned}
$$


Table 1(a): Comparison of our research with recent research literature

\begin{tabular}{|c|c|c|c|c|c|c|c|c|c|}
\hline \multirow[t]{2}{*}{ Authors } & \multicolumn{3}{|c|}{ Sustainability related dimensions } & \multicolumn{6}{|c|}{ DEA efficiency measurement modeling } \\
\hline & Social & Environmental & Economic & $\begin{array}{c}\text { Composite } \\
\text { measure }\end{array}$ & $\begin{array}{c}\text { Single- } \\
\text { objective } \\
\text { efficiency } \\
\text { model }\end{array}$ & $\begin{array}{c}\text { Bi- } \\
\text { objective } \\
\text { efficiency } \\
\text { model }\end{array}$ & $\begin{array}{c}\text { Multi- } \\
\text { objective } \\
\text { efficiency } \\
\text { model }\end{array}$ & $\begin{array}{c}\text { Trade-offs } \\
\text { amongst } \\
\text { different } \\
\text { efficiency } \\
\text { categories }\end{array}$ & $\begin{array}{c}\text { Simultaneous } \\
\text { consideration of } \\
\text { desirable and } \\
\text { undesirable outputs }\end{array}$ \\
\hline $\begin{array}{l}\text { D'Inverno et } \\
\text { al. (2018) }\end{array}$ & & \# & & \# & \# & \# & & & \# \\
\hline $\begin{array}{c}\text { Park et al., } \\
(2018)\end{array}$ & & \# & & \# & \# & & & & \\
\hline $\begin{array}{c}\text { Fukuyama et } \\
\text { al., (2017) }\end{array}$ & \# & & \# & \# & \# & & & & \# \\
\hline $\begin{array}{l}\text { Tsaur et al., } \\
\text { (2017) }\end{array}$ & & & \# & & \# & & & \# & \\
\hline $\begin{array}{c}\text { Moheb- } \\
\text { Alizadeh et } \\
\text { al., (2017) }\end{array}$ & & \# & \# & & & \# & & & \\
\hline $\begin{array}{c}\text { Shaw et al, } \\
(2016)\end{array}$ & \# & \# & \# & \# & \# & & & & \# \\
\hline $\begin{array}{l}\text { Balezentis et } \\
\text { al., (2016) }\end{array}$ & & \# & & & \# & & & & \# \\
\hline $\begin{array}{c}\text { Dotoli et al., } \\
\text { (2016) }\end{array}$ & & & \# & \# & \# & & & & \# \\
\hline $\begin{array}{l}\text { Azadnia et } \\
\text { al., (2015) }\end{array}$ & \# & \# & \# & \# & & & \# & & \\
\hline $\begin{array}{l}\text { Azadi et al., } \\
(2015)\end{array}$ & \# & \# & \# & \# & \# & & & & \\
\hline $\begin{array}{c}\text { Karsak et al., } \\
(2014)\end{array}$ & & \# & \# & \# & \# & & & & \# \\
\hline $\begin{array}{c}\text { Govindan et } \\
\text { al., (2014) }\end{array}$ & \# & \# & \# & \# & $\#$ & & & & \\
\hline $\begin{array}{c}\text { Proposed } \\
\text { research }\end{array}$ & \# & \# & \# & \# & \# & \# & & \# & \# \\
\hline
\end{tabular}

\# means that the particular dimension(s) were captured and discussed in the particular article

Table 1(b): A generalized cross-efficiency matrix

Rating

DMU "s"
Rated

DMU " $d$ "

\begin{tabular}{|c|c|c|c|c|c|c|}
\hline & 1 & 2 & 3 & 4 & & $\mathrm{~S}$ \\
\hline 1 & - & $C E_{12}(J K)$ & $C E_{13}(J K)$ & $C E_{14}(J K)$ & $C E_{1 .}(J K)$ & $C E_{I S}(J K)$ \\
\hline 2 & $C E_{21}(J K)$ & - & $C E_{23}(J K)$ & $C E_{24}(J K)$ & $C E_{2 .}(J K)$ & $C E_{2 S}(J K)$ \\
\hline 3 & $C E_{31}(J K)$ & $C E_{32}(J K)$ & - & $C E_{34}(J K)$ & $C E_{3 .}(J K)$ & $C E_{3 S}(J K)$ \\
\hline 4 & $\begin{array}{l}C E_{41}(J K) \\
C E_{1}(J K)\end{array}$ & $\begin{array}{l}C E_{42}(J K) \\
C E_{2}(J K)\end{array}$ & $\begin{array}{l}C E_{43}(J K) \\
C E_{3}(J K)\end{array}$ & ${ }^{-}-$ & $C E_{4 .}(J K)$ & $\begin{array}{l}C E_{3 S}(J K) \\
C E_{S}(J K)\end{array}$ \\
\hline$S$ & $C E_{S 1}(J K)$ & $C E_{S 2}(J K)$ & $C E_{S 3}(J K)$ & $C E_{S 4}(J K)$ & $C E_{S .}(J K)$ & - \\
\hline
\end{tabular}


Table 2: Dataset of Hyundai Steel Company's suppliers

\begin{tabular}{|c|c|c|c|c|c|c|}
\hline Suppliers & $\begin{array}{c}\text { Number } \\
\text { of } \\
\text { employees }\end{array}$ & $\begin{array}{c}\text { Energy } \\
\text { consumption } \\
\text { (kW h/yr.) }\end{array}$ & $\begin{array}{c}\text { Sales } \\
(\mathbf{1 0 0 0} \\
\text { Korean } \\
\text { Won) }\end{array}$ & ROA & $\begin{array}{c}\text { Environmental } \\
\text { R\&D investment } \\
\mathbf{( 1 0 0 , 0 0 0 \text { Korean }} \\
\text { Won) }\end{array}$ & $\begin{array}{c}\mathbf{C O}_{\mathbf{2}} \\
\text { emission } \\
\mathbf{( k g})\end{array}$ \\
\hline 1 & 1112 & 1267 & 119,477 & 0.04046 & 67 & 43,562 \\
\hline 2 & 118 & 968 & 125,762 & 0.04499 & 65 & 45,000 \\
\hline 3 & 458 & 1001 & 58,770 & 0.02221 & 57 & 42,400 \\
\hline 4 & 416 & 1393 & 62,989 & 0.02920 & 62 & 43,734 \\
\hline 5 & 413 & 1586 & 67,088 & 0.03269 & 50 & 44,890 \\
\hline 6 & 430 & 1802 & 72,318 & 0.03116 & 36 & 42,913 \\
\hline 7 & 426 & 1998 & 74,626 & 0.02184 & 47 & 39,438 \\
\hline 8 & 452 & 1824 & 74,476 & 0.03480 & 44 & 40,078 \\
\hline 9 & 503 & 1479 & 79,710 & 0.03976 & 47 & 39,500 \\
\hline 10 & 498 & 1623 & 79,384 & 0.03723 & 89 & 45,023 \\
\hline 11 & 192 & 1322 & 73,124 & 0.01269 & 256 & 41,324 \\
\hline 12 & 171 & 831 & 62,529 & 0.00385 & 423 & 45,000 \\
\hline 13 & 163 & 913 & 65,424 & 0.02776 & 508 & 42,400 \\
\hline 14 & 161 & 893 & 71,027 & 0.04847 & 536 & 43,734 \\
\hline 15 & 161 & 903 & 74,093 & 0.05140 & 570 & 44,890 \\
\hline 16 & 162 & 778 & 72,830 & 0.04356 & 472 & 42,913 \\
\hline 17 & 159 & 710 & 71,940 & 0.03932 & 426 & 39,438 \\
\hline 18 & 157 & 695 & 82,203 & 0.02599 & 386 & 40,078 \\
\hline 19 & 151 & 637 & 55,681 & 0.00001 & 376 & 39,500 \\
\hline 20 & 151 & 781 & 64,839 & 0.02742 & 369 & 38,570 \\
\hline
\end{tabular}


Table 3: Number of expressions in augmented form

Table 3(a): Single-objective efficiency model (for all 20 linear models)

\begin{tabular}{|c|c|c|}
\hline Expressions related to & $\begin{array}{c}\text { Corresponding equation } \\
\text { no. }\end{array}$ & Numbers \\
\hline $\begin{array}{c}\text { Objective function(s) } \\
\begin{array}{c}\text { Constraint(s) related to interlinked } \\
\text { desirable and undesirable outputs }\end{array}\end{array}$ & 27 & 1 \\
\hline $\begin{array}{c}\text { Constraint(s) related to respective } \\
\text { input(s) }\end{array}$ & 28 & 20 \\
\hline $\begin{array}{c}\text { Constraint(s) related to weight of } \\
\text { desirable output(s) }\end{array}$ & 31 & 1 \\
\hline $\begin{array}{c}\text { Non- negativity constraint(s) related to } \\
\text { weight of undesirable output(s) }\end{array}$ & 32 & 2 \\
\hline $\begin{array}{c}\text { Non- negativity constraints related to } \\
\text { weight of input(s) }\end{array}$ & 29 \\
\hline
\end{tabular}

Table 3(b): Equivalent model for the bi-objective efficiency model (for all 20 linear models)

\begin{tabular}{|c|c|c|}
\hline Expressions related to & $\begin{array}{c}\text { Corresponding equation } \\
\text { no. }\end{array}$ & Numbers \\
\hline $\begin{array}{c}\text { Objective function(s) } \\
\text { Constraint(s) on goal of desirable } \\
\text { output(s) }\end{array}$ & 35 & 60 \\
\hline $\begin{array}{c}\text { Constraint(s) on goal of undesirable } \\
\text { output(s) }\end{array}$ & 36 & 20 \\
\hline $\begin{array}{c}\text { Constraints(s) related to importance of } \\
\text { desirable and undesirable output(s) }\end{array}$ & 38 & 1 \\
\hline $\begin{array}{c}\text { Non-negativity constraint(s) related to } \\
\text { deviation of undesirable output(s) }\end{array}$ & 39 & 3 \\
\hline $\begin{array}{c}\text { Non-negativity constraint(s) related to } \\
\text { deviation of undesirable output(s) }\end{array}$ & 40 & 1 \\
\hline
\end{tabular}


Table 4: Optimal weights of factors obtained by single-objective efficiency model

\begin{tabular}{|c|c|c|c|c|c|c|c|c|c|}
\hline Suppliers & $u_{1}^{*}$ & $u_{2}^{*}$ & $v_{1}^{*}$ & $v_{2}^{*}$ & $v_{3}^{*}$ & $w_{1}^{*}$ & $\begin{array}{r}\text { Efficiency } \\
(\%)\end{array}$ & Rankings & Discarded efficiency \\
\hline Supplier 1 & 0.0000010000 & 0.0007883883 & 0.0000062449 & 0.0000010000 & 0.0003523273 & 0.0000010000 & 72.61 & 11 & $\mathrm{ROA} / \mathrm{CO}_{2}$ emission \\
\hline Supplier 2 & 0.0000010000 & 0.0010329360 & 0.0000037050 & 12.8692024331 & 0.0000010000 & 0.0000010000 & 100 & 1 & $\begin{array}{l}\text { Env. } \mathrm{R} \& \mathrm{D} \\
\text { invest } / \mathrm{CO}_{2} \text { emission }\end{array}$ \\
\hline Supplier 3 & 0.0000010000 & 0.0009985435 & 0.0000035818 & 12.4735535548 & 0.0000010000 & 0.0000010000 & 44.51 & 15 & $\begin{array}{l}\text { Env. R \& D } \\
\text { invest } / \mathrm{CO}_{2} \text { emission }\end{array}$ \\
\hline Supplier 4 & 0.0000010000 & 0.0007175765 & 0.0000025755 & 9.2413285252 & 0.0000010000 & 0.0000010000 & 38.84 & 17 & $\begin{array}{l}\text { Env. } \mathrm{R} \& \mathrm{D} \\
\text { invest } / \mathrm{CO}_{2} \text { emission }\end{array}$ \\
\hline Supplier 5 & 0.0000010000 & 0.0006302566 & 0.0000052094 & 0.0000010000 & 0.0000010000 & 0.0000010000 & 46.09 & 14 & $\begin{array}{l}\text { ROA/Env. R \& D } \\
\text { invest } / \mathrm{CO}_{2} \text { emission }\end{array}$ \\
\hline Supplier 6 & 0.0000010000 & 0.0005547003 & 0.0000019921 & 7.3676128617 & 0.0000010000 & 0.0000010000 & 33.07 & 19 & $\begin{array}{l}\text { Env. } \mathrm{R} \& \mathrm{D} \\
\text { invest } / \mathrm{CO}_{2} \text { emission }\end{array}$ \\
\hline Supplier 7 & 0.0000010000 & 0.0005002873 & 0.0000040873 & 0.0000010000 & 0.0002365349 & 0.0000010000 & 27.66 & 20 & $\mathrm{ROA} / \mathrm{CO}_{2}$ emission \\
\hline Supplier 8 & 0.0000010000 & 0.0005479978 & 0.0000019681 & 7.2905074653 & 0.0000010000 & 0.0000010000 & 36.02 & 18 & $\begin{array}{l}\text { Env. } \mathrm{R} \& \mathrm{D} \\
\text { invest } / \mathrm{CO}_{2} \text { emission }\end{array}$ \\
\hline Supplier 9 & 0.0000010000 & 0.0006757924 & 0.0000024153 & 12.4636845572 & 0.0000010000 & 0.0000046727 & 50.03 & 13 & Env. R \& D invest \\
\hline Supplier 10 & 0.0000010000 & 0.0006158361 & 0.0000022111 & 8.0709145795 & 0.0000010000 & 0.0000010000 & 43.10 & 16 & $\begin{array}{l}\text { Env. R \& D } \\
\text { invest } / \mathrm{CO}_{2} \text { emission }\end{array}$ \\
\hline Supplier 11 & 0.0052014479 & 0.0000010000 & 0.0000047652 & 0.0000010000 & 0.0009301007 & 0.0000010000 & 54.42 & 12 & $\mathrm{ROA} / \mathrm{CO}_{2}$ emission \\
\hline Supplier 12 & 0.0000010000 & 0.0012031637 & 0.0000029091 & 0.0000010000 & 0.0016069533 & 0.0000010000 & 81.66 & 10 & $\begin{array}{l}\text { Env. R \& D } \\
\text { invest } / \mathrm{CO}_{2} \text { emission }\end{array}$ \\
\hline Supplier 13 & 0.0000010000 & 0.0010951117 & 0.0000010000 & 0.0000010000 & 0.0016839365 & 0.0000010000 & 87.84 & 8 & $\begin{array}{l}\text { Sales/ROA } / \mathrm{CO}_{2} \\
\text { emission }\end{array}$ \\
\hline Supplier 14 & 0.0024120861 & 0.0006849430 & 0.0000074392 & 0.0000010000 & 0.0008781495 & 0.0000010000 & 95.53 & 6 & $\mathrm{ROA} / \mathrm{CO}_{2}$ emission \\
\hline Supplier 15 & 0.0062055714 & 0.0000010000 & 0.0000010000 & 13.8455900841 & 0.0004546205 & 0.0000010000 & 100 & 1 & $\begin{array}{l}\text { Sales/ Env. R \& D } \\
\text { invest/ } \mathrm{CO}_{2} \text { emission }\end{array}$ \\
\hline Supplier 16 & 0.0000010000 & 0.0012851388 & 0.0000019559 & 20.6234060782 & 0.0000010000 & 0.0000010000 & 99.83 & 4 & $\begin{array}{l}\text { Env. R \& D } \\
\text { invest } / \mathrm{CO}_{2} \text { emission }\end{array}$ \\
\hline Supplier 17 & 0.0006780404 & 0.0012566079 & 0.0000035100 & 20.0026869812 & 0.0000010000 & 0.0000010000 & 100 & 1 & $\begin{array}{l}\text { Env. } \mathrm{R} \& \mathrm{D} \\
\text { invest } / \mathrm{CO}_{2} \text { emission }\end{array}$ \\
\hline Supplier 18 & 0.0000010000 & 0.0014386230 & 0.0000111148 & 0.0000010000 & 0.0006136671 & 0.0000010000 & 99.80 & 5 & $\mathrm{ROA} / \mathrm{CO}_{2}$ emission \\
\hline Supplier 19 & 0.0000010000 & 0.0015696217 & 0.0000036862 & 0.0000010000 & 0.0020864905 & 0.0000010000 & 95.02 & 7 & $\mathrm{ROA} / \mathrm{CO}_{2}$ emission \\
\hline Supplier 20 & 0.0026832792 & 0.0007616195 & 0.0000082349 & 0.0000010000 & 0.0009727866 & 0.0000010000 & 85.43 & 9 & $\mathrm{ROA} / \mathrm{CO}_{2}$ emission \\
\hline
\end{tabular}

Table 5: Dominant efficiency categories

\begin{tabular}{|c|c|}
\hline Dominant efficiency factors & Supplier(s) \\
\hline Sales/ROA/CO COmission $_{2}$ & $(9)$ \\
\hline Sales/Env. R\&D invest. & $(1,7,11,14,18,19,20)$ \\
\hline Sales/ROA & $(2,3,4,6,8,10,12,16,17)$ \\
\hline Sales & $(5,14)$ \\
\hline ROA & $(13,15)$ \\
\hline
\end{tabular}


Table 6: Rankings of suppliers in respective categories

\begin{tabular}{|c|c|c|c|c|c|}
\hline \multirow{2}{*}{ Rankings } & \multicolumn{5}{|c|}{ Dominant efficiency categories } \\
\cline { 2 - 6 } & $\begin{array}{c}\text { Sales/ROA/CO } \\
\text { emission }\end{array}$ & $\begin{array}{c}\text { Sales/Env. } \\
\text { R\&D } \\
\text { invest. }\end{array}$ & Sales/ROA & Sales & ROA \\
\hline 1 & Supplier 9 & Supplier 18 & $\begin{array}{c}\text { Supplier 17 } \\
\text { and supplier } \\
2\end{array}$ & Supplier 14 & Supplier 15 \\
\hline 2 & & Supplier 14 & - & Supplier 5 & Supplier 13 \\
\hline 3 & & Supplier 19 & Supplier 16 & & \\
\hline 4 & & Supplier 20 & Supplier 12 & & \\
\hline 5 & & Supplier 1 & Supplier 3 & & \\
\hline 6 & & Supplier 11 & Supplier 10 & & \\
\hline 7 & & Supplier 7 & Supplier 4 & & \\
\hline 8 & & & Supplier 8 & & \\
\hline 9 & & & Supplier 6 & & \\
\hline
\end{tabular}




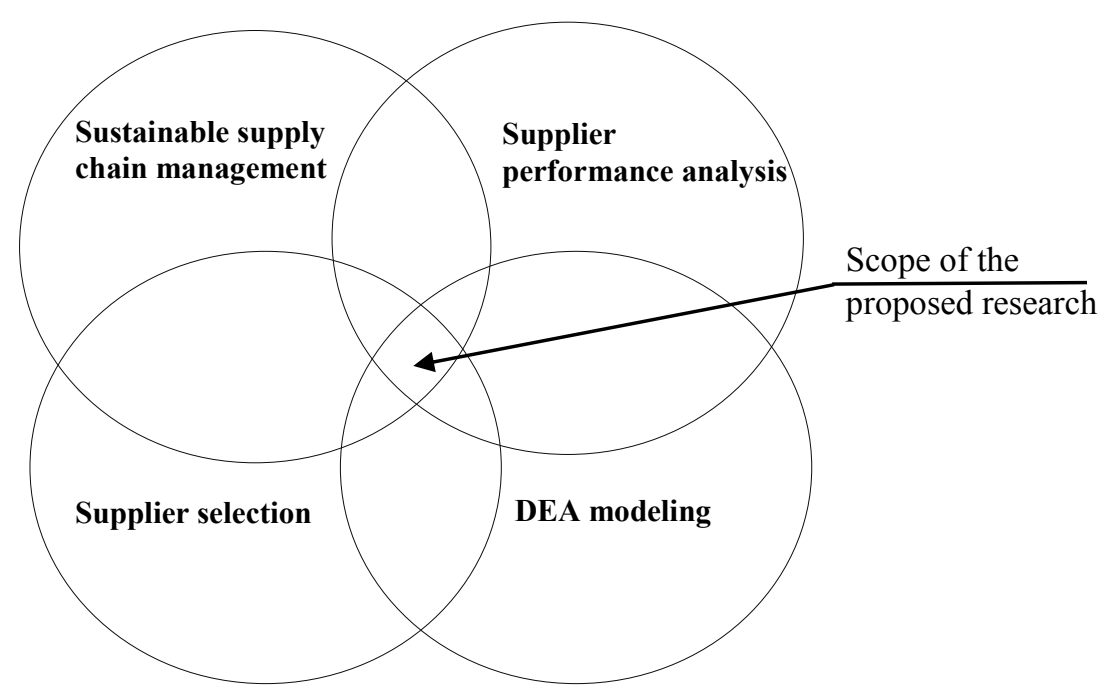

Figure 1(a): Scope of our research

\section{Individual efficiency evaluation}

\section{Cross efficiency evaluation}

\section{Single objective efficiency model \\ Maximize \{Composite efficiency for suppliers\} s.t. \\ - Input-output conversion constraint \\ - Scaled input constraint \\ - Non-negativity of parameters' weights constraint}

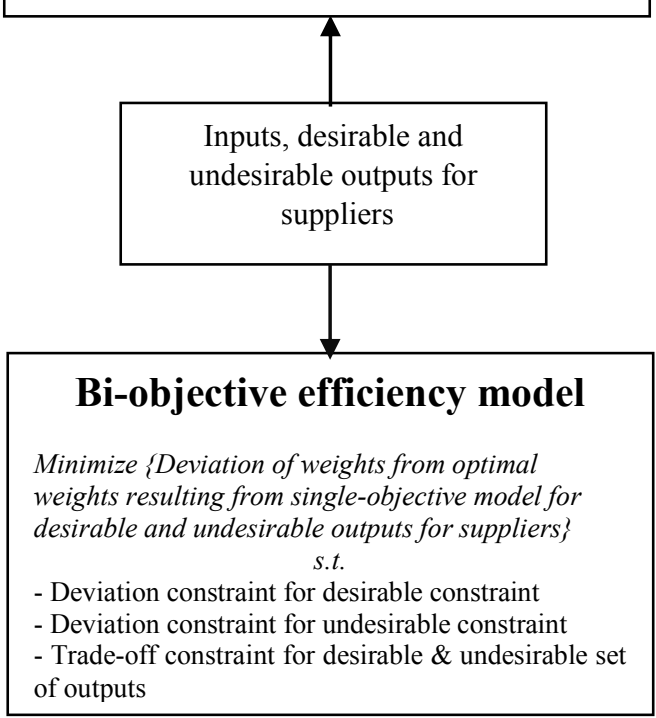

\section{Single objective efficiency model}

Maximize \{Composite efficiency for suppliers\} s.t.

- Input-output conversion constraint

- Scaled input constraint

- Non-negativity of parameters' weights constraint

- Peer to peer comparison constraint

Three dimensional cross efficiency frontier for suppliers with improved discrimination
Supplier rankings based on trade-offs between desirable and undesirable outputs

Optimal deviation values for both desirable and undesirable set of outputs

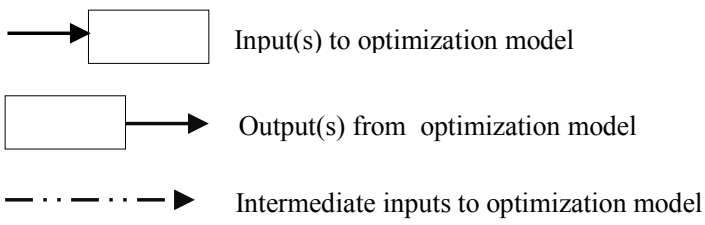

Figure 1(b): Research schema of proposed framework

Figure 1: Research scope and broad schema of research framework 


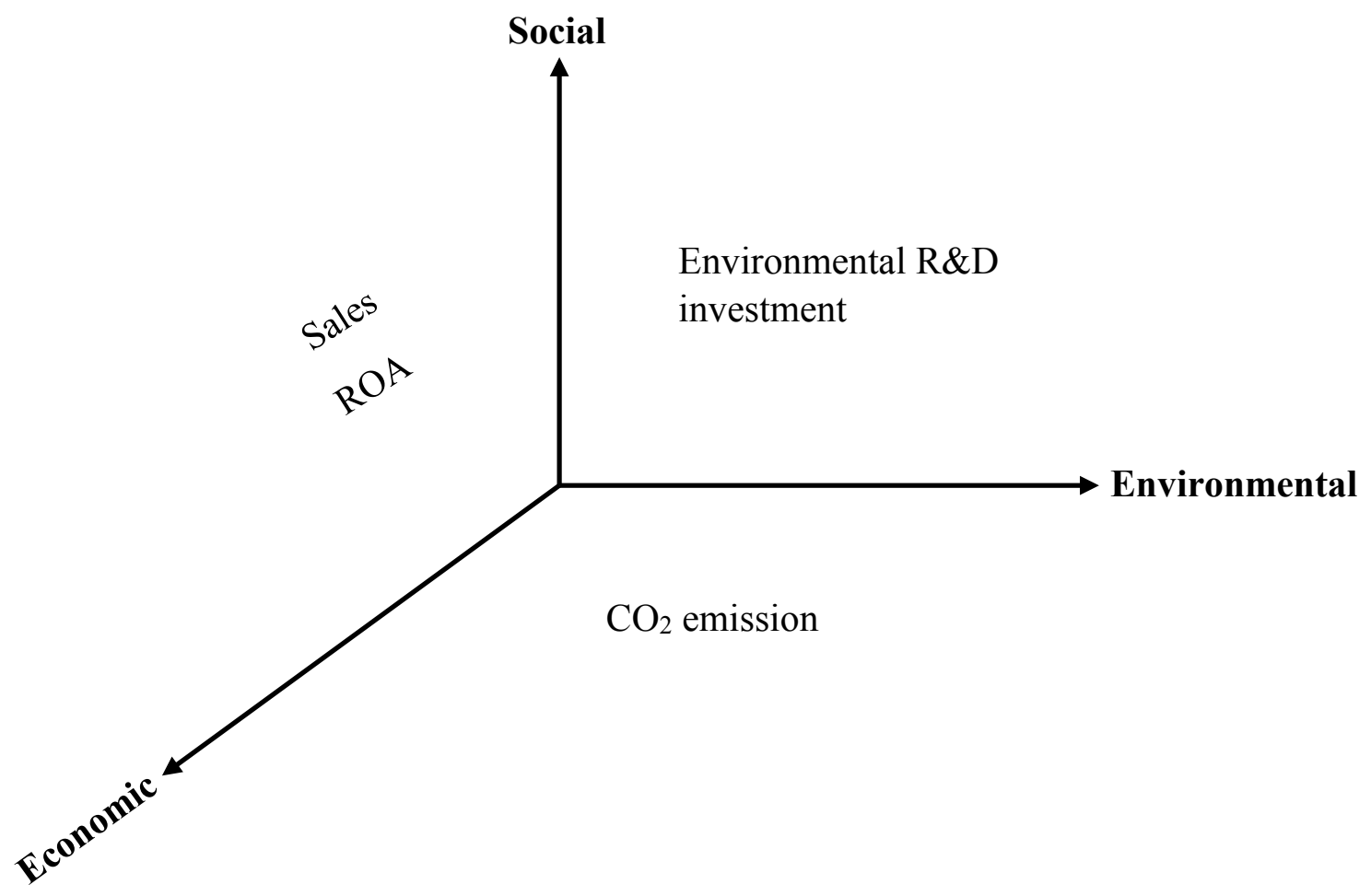

Figure 2: Position of outputs (desirable and undesirable) on sustainability planes

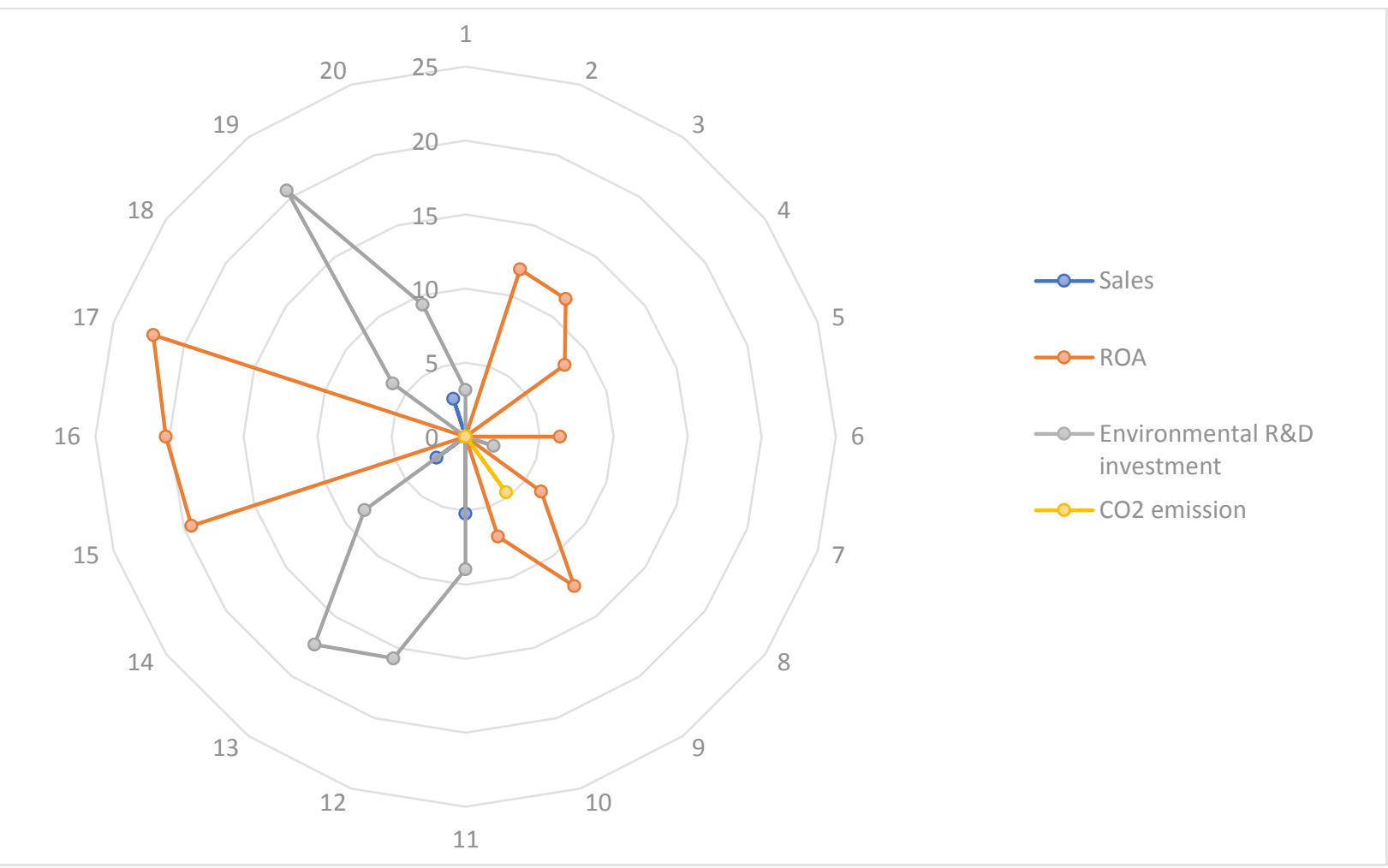


Figure 3(a): Spread of output weight for 20 suppliers

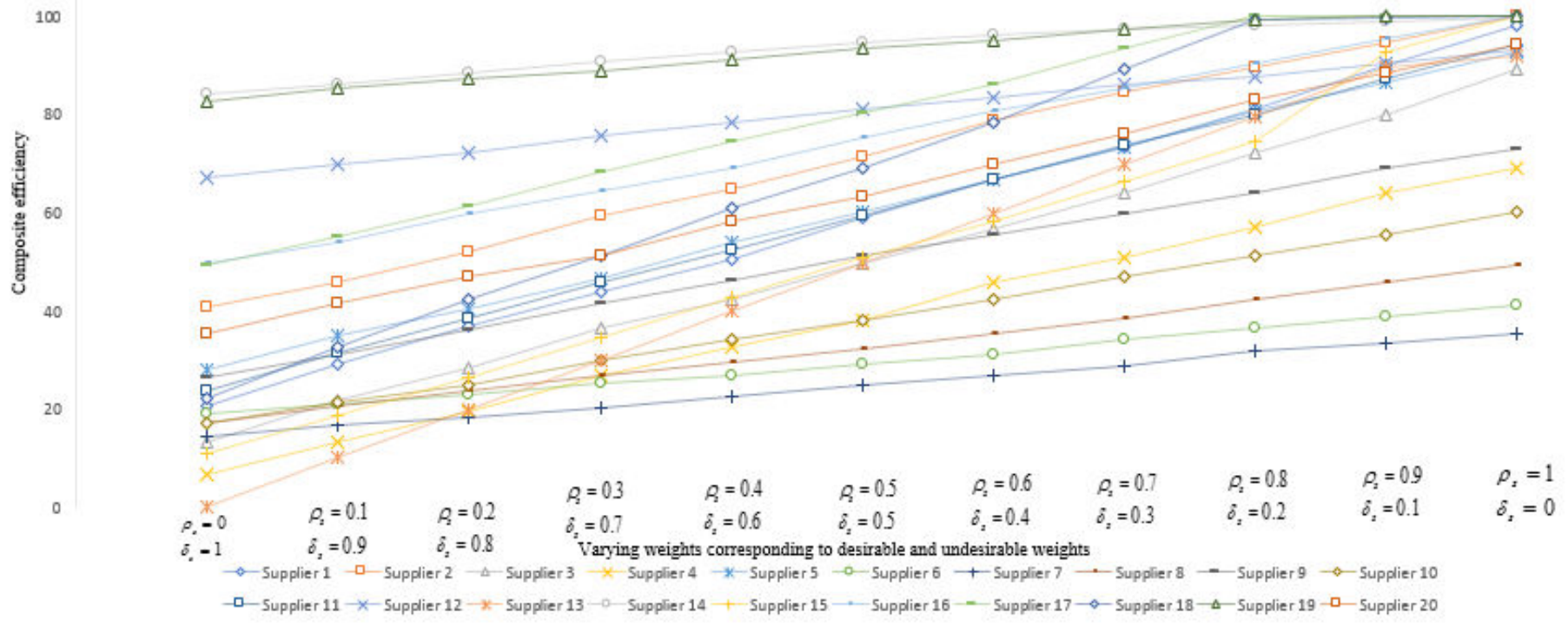

Figure 3(b): Efficiency characteristics with varying weight for desirable and undesirable outputs

Figure 3: Spread of output weights and efficiency characteristics

\section{Cross efficiencies of individual suppliers $(\rho s=0.5$ and $\delta s=0.5)$}

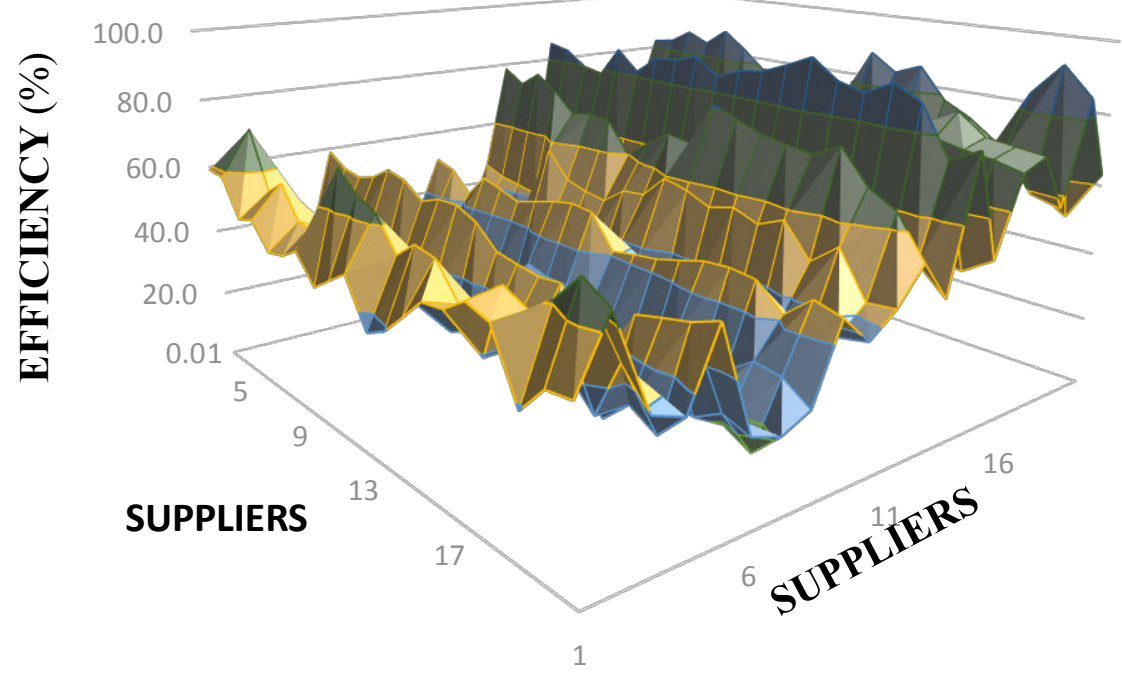

$\square$ 0.0-20.0 $\square 20.0-40.0 \quad \square$ 40.0-60.0 $\square 60.0-80.0 \quad \square 80.0-100.0$

Figure 4(a): Cross efficiencies when desirable and undesirable output set assumes equal importance 


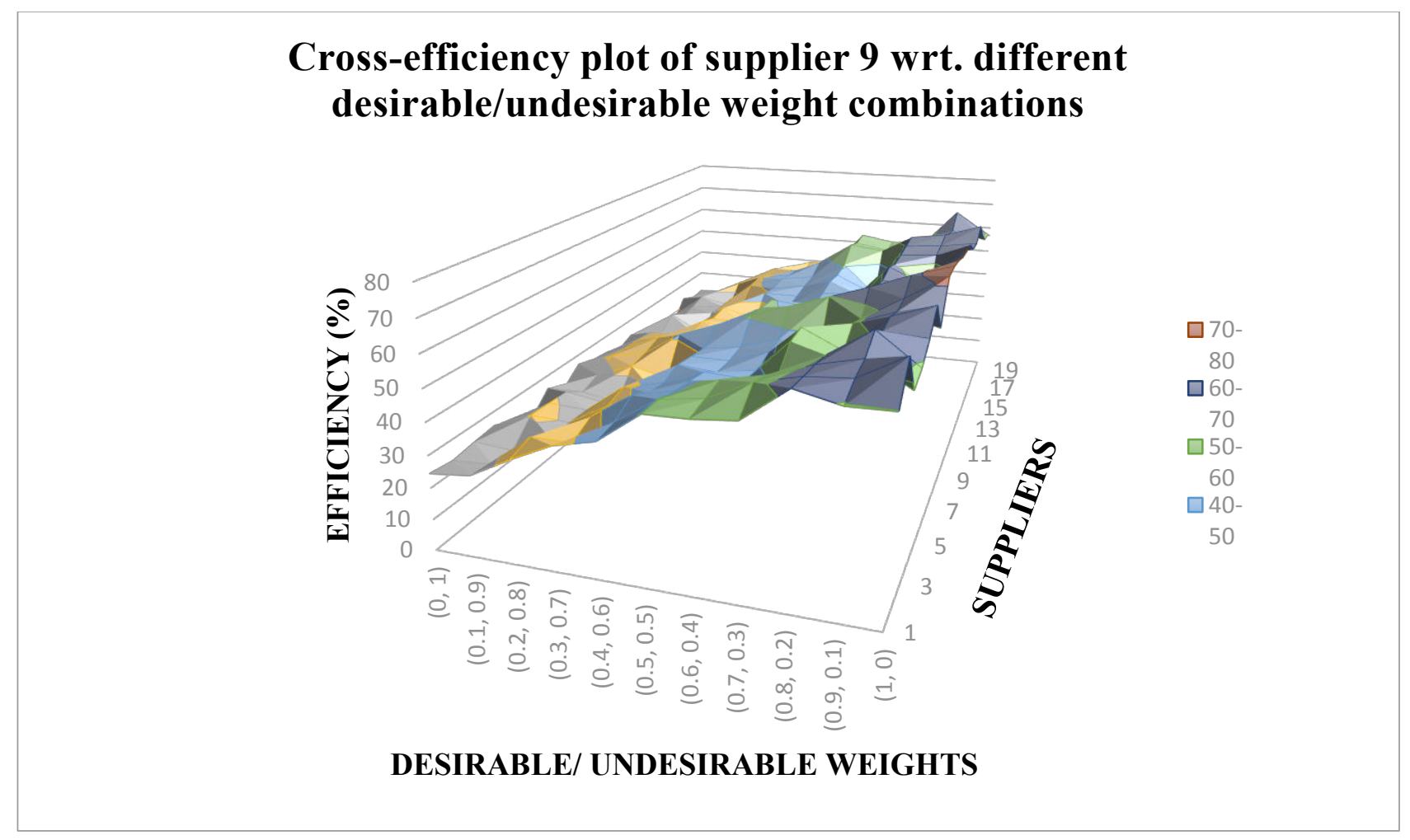

Figure 4(b): Plot of cross-efficiency plot for supplier 9 wrt. varying weights of desirable and desirable outputs 